\title{
Small RNA and Degradome Analyses Uncovering the Extensive Effects of miRNAs and Targets in Early Developing Grains of Common Wheat
}

\author{
Qiaoyan Chen \\ Henan Institute of Science and Technology \\ Lina Xu \\ Henan Institute of Science and Technology \\ Yuanyuan Guan \\ Henan Institute of Science and Technology \\ Zeeshan Ali Buttar \\ Henan Institute of Science and Technology \\ Gan Li \\ Henan Institute of Science and Technology

\section{Guang Zhang} \\ Henan Institute of Science and Technology \\ Chunxiao Li \\ Henan Institute of Science and Technology \\ Jinyong Huang \\ Zhengzhou University \\ Mingjiu Liu \\ Henan Institute of Science and Technology \\ Wenhui Wei ( $\square$ whwei88@hotmail.com ) \\ Henan Institute of Science and Technology
}

\section{Research article}

Keywords: Triticum aestivum, MicroRNAs, Degradome, Target genes, Grain development

Posted Date: December 10th, 2020

DOI: https://doi.org/10.21203/rs.3.rs-123517/v1

License: (9) (1) This work is licensed under a Creative Commons Attribution 4.0 International License. Read Full License 


\section{Abstract}

Background: The development of grains is important for wheat production, and wheat (Triticum aestivum) is one of the staple food crops worldwide. MicroRNAs (miRNAs), as a kind of small regulatory RNAs, play important roles during plant growth and development. Although the development of plant grain/seed is widely researched, there is limited knowledge on miRNAs's regulation of early developing wheat grains.

Results: In the present study, miRNAs and their targets were explored in early developing grains of wheat cultivar "Bainong 4199" at 7DAP and 14 DAP using high-throughput small RNA and degradome sequencing. A total of 105 known and 79 novel miRNAs were identified, including 46 known and 32 novel miRNAs from 7 DAP library and 87 known and 78 novel miRNAs from 14 DAP library, respectively. Expression analysis of miRNAs revealed that 39 miRNAs including 19 known and 20 novel miRNAs were differentially expressed between 7 DAP and 14 DAP. In total, 266 targets for 40 known wheat miRNAs, 152 targets for 13 other known plant miRNAs and 258 targets for 25 novel miRNAs were predicted across small RNA and degradome analyses. For differentially expressed miRNAs, 23 targets were predicted to be cleaved by 7 miRNAs, including 3 known and 4 novel miRNAs. Majority of the miRNAs potentially regulated multiple targets, whereas some miRNAs only acted on a single target gene. Functional analyses showed that miRNAs and their targets widely participated in the regulations of early wheat grain development and metabolism. The expression patterns of the randomly selected miRNAs and targets were validated using quantitative real-time polymerase chain reaction, and showed consistent and reliable results.

Conclusion: This study suggests that quite a few known and novel miRNAs and their targets play extensive roles during the early grain development of common wheat. Understanding of miRNA-mediated regulatory network involved in wheat grain development will help us to elucidate the molecular mechanisms underlying wheat grain development and carry out ingenious molecular improvements in wheat breeding.

\section{Background}

Common wheat (Triticum aestivum) is a staple food crop cultivated worldwide. Grain development is important for determining the end yield and quality of wheat [1]. Grain size and plumpness determine grain weight [2]. The association between grain weight and grain volume at physiological maturity or harvest has been studied [3]. Early grain development symbolically represents a rapid increase in grain volume after fertilization. The first dimension reaching maximum value is grain length ( 15 DAP, days after pollination), which is best correlated with ultimate grain weight and volume [4]. Based on morphological and metabolite changes, grain development is divided into pattern formation, maturation and desiccation stages. The transition to maturation stage occurs at 5 DAP to 10 DAP; this transition initiates tissues differentiation [5]. At the same time, maturation stage lasts up to approximately 25 DAP [5], and studies have shown that seed weight increases rapidly between 12 and 18 DAP and continues to add until 30 DAP [1]. Furthermore, the weight, morphology, protein content, size and shape of grains have been researched [6]. Research on wheat grain weight has also been carried out by QTLs of thousand-grain weight [7] and grains filling [8].

MicroRNAs (miRNAs) are small RNAs playing key regulatory roles in gene post-transcriptional abundance in plants and animals [9, 10]. In plants, primary miRNAs (pri-miRNAs) are initially transcribed from miRNA genes by RNA polymerase II, and then the precursor miRNAs (pre-miRNAs) of miRNA/miRNA* duplex were produced via intermediate hairpin structure products [11]. MiRNAs are produced from the pre-miRNAs of miRNA/miRNA* duplex by RNase III enzyme DCL1 or DCL4 [12]. Mature miRNAs are transported to RNA-induced silencing complex (RISC), and then RISC guides miRNAs to respective targets to suppress gene expression via mRNA cleavage or translational inhibition [13]. MiRNA could be authenticated by computational identification [14], experimental identification [15], expression profiling with microarray technology [16], and high-throughput sequencing technology [17]. To date, the number of miRNAs identified has exponentially increased in plants, and these miRNAs can be searched from miRBase (Release 22.0, March 2018; http://www.mirbase.org). Based on miRBase, it is found that some miRNA genes are conserved between plant species, and more miRNA genes are species-specific [18].

Former studies showed that miRNAs played important roles in the regulations of plant development and organ identity [19], and in the responses to biotic and abiotic stresses [20]. It is paid more attention to that miRNAs regulate the development of seeds/grains in many plant species, such as Arabidopsis [21], maize [22], rice [23], wheat [1] , barley [24] and Brassica napus [25]. Most miRNAs presented higher abundance in the grains of 6 to 10 DAP compared to those of 1 to 5 DAP in rice [26]. In wheat grains, about half of 
the detected miRNAs were up-regulated from 5 DAP to 20 DAP, and miR164 and miR160 increased abundantly during grain development [27]. Under the condition of over-expression, miR397 gave rise to an increase of grain yield by enlarging grain size and promoting panicle branching in rice [28].

MiRNAs in wheat were identified from seeding [29], flag leaf and developing seed [27,30], callus [31], germ extract, leaves, roots, spikes and multiple tissues [32]. The identification methods used mainly include high-throughput sequencing, in silico prediction and wet-lab validation [33]. To date, it has been found that wheat miRNAs take part in the regulations of grain development [34], stripe rust resistance [30], powdery mildew resistance and heat stress response [35], as well as cold stress response [16], etc.

Degradome sequencing is an effective means in studies of degraded mRNAs. This technology could identify the target mRNAs of miRNAs on a large scale when it is combined with high-throughput sequencing and bioinformatics analysis to search for miRNAguided cleavage sites in mRNAs [36]. In the same way, combined with small RNA sequencing, some novel miRNAs with low abundance and their targets could be identified successively $[37,38]$. In wheat, some miRNAs and their targets have been effectively studied with small RNA and degradome sequencing $[39,40]$.

The early stage of grain development is an important period for determining grain yield and quality characteristics for wheat harvest. However, the regulation of grain development is unclear during the early stage. In the present study, wheat grains at 7 DAP and 14 DAP, which represent two transitional early developmental phases of wheat grains, were isolated. High-throughput small RNA and degradome sequencing were performed to explore the miRNAs and their target genes possibly participating in the regulation of early grain development.

\section{Results}

\section{Phenotypic analysisof developing grain}

The development of wheat grain was evaluated by monitoring the pattern of increased grain weight and volume. Here, the growth of grain weight and volume was relatively slow at the early stage (before 11 DAP), increased sharply across 11 to 14 DAP and continued to rise until about 26 DAP (Fig. 1A). The appearances of developing grains at some representative time points are shown in Fig. 1B. Based on the pattern, we focused mainly on the transitional phases at 7 DAP and 14 DAP, the key periods for early grain development. To reveal the relevance between these changes and miRNAs abundance during early grain development, we then used the small RNA and degradome libraries from 7 DAP and 14 DAP grains to compare the expression of miRNAs and analyze the possible functions of their targets.

\section{Deep-sequencing of sRNAs in early developing grains}

To uncover the roles of miRNAs during wheat grains development at early stage after pollination, the grains of cultivar "Bainong 4199" at 7 DAP and 14 DAP were used to construct two small RNA libraries and then they were sequenced. Firstly, 22,900,708 raw reads from 7DAP and 20,279,914 raw reads from 14 DAP were produced, respectively. Then, the low-quality reads were filtered, adapter sequences and sequences of less than $18 \mathrm{nt}$ and more than $30 \mathrm{nt}$ were removed. Finally, 14,020,684 and 10,379,004 clean sRNAs were obtained from 7 DAP and 14 DAP libraries, respectively (Table 1). The length of clean sRNAs ranged from 18 to $30 \mathrm{nt}$ in the two libraries. Majority of the clean sRNAs were $21-24 \mathrm{nt}$ in length. It is found that the most common length is $21 \mathrm{nt}$ in the 7 DAP library and $24 \mathrm{nt}$ in the 14 DAP library (Fig. 2).

Non-coding RNAs, such as tRNA, rRNA, small nuclear RNA (snRNA), small nucleolar RNA (snoRNA) and small cytoplasmic RNA (scRNA), were determined based on the databases of Rfam (http://rfam.xfam.org) and RepBase (http://www.girinst.org/repbase/). After removing the annotated RNAs (tRNA, rRNA, Repbase, and snoRNA), the number of the remaining unannotated sequences was 2,320,782 (accounted for 16.56\%) in 7 DAP library and 3,387,722 (32.64\%) in 14 DAP library of clean reads (Table 2). Of these unannotated sequences, 235,879 (10.64 \%) reads in 7 DAP library and 1,458,680 (43.06\%) reads in 14 DAP library were matched perfectly to those from the whole genome shotgun (WGS) assembly

(http://mips.helmholtzmuenchen.de/plant/wheat/uk454survey/index.jsp) and the National Center for Biotechnology Information (NCBI) (Additional file 1). 


\section{Identification of known miRNAs}

To identify known miRNAs, we compared the unannotated sRNA sequences that matched perfectly to reference genome against miRBase 22.0 (http://www.mirbase.org) based on perfect match criterion. A total of 89 known miRNAs from wheat were detected in miRBase/ Triticum aestivum in the two sRNA libraries, of which 46 were expressed in 7 DAP library and 87 were expressed in 14 DAP library (Additional file 2). Of the known miRNAs from other plant species, their secondary structure and miRNAs* were predicted based on RNAfold (http://rna.tbi.univie.ac.at/cgi-bin/RNAfold.cgi), and these miRNAs were predicted based on MIREAP (http://sourceforge.net/projects/mireap/) by analyzing DCL1 cleavage sites and the minimum free energy. A total of 16 known miRNAs from other plant species were identified in the present two sRNA libraries, with 13 expressed in 7 DAP library and 16 expressed in 14 DAP library (Table 3; Additional file 2). The secondary structures of these miRNAs are shown in Additional file 3.

As the expression of the known miRNA, ata-miR9863a-3p, osa-miR396e-5p, tae-miR9670-3p and tae-miR7757-5p were most abundantly expressed, while some miRNAs such as tae-miR9672b, tae-miR9662a-3p, tae-miR167c-5p, tae-miR156, tae-miR9777 and tae-miR9669-5p were moderately abundant (Fig. 3). Majority of the abundantly expressed miRNAs were known miRNAs from wheat miRBase and conserved miRNAs between plant species, such as miR156, miR396e-5p (Additional file 2).

\section{Predicted novel miRNAs}

To predict novel miRNAs, the unannotated sRNAs were analyzed on the basis of pre-miRNA sequences that can form a canonical stem-loop hairpin structure [41]. A total of 79 novel miRNAs were predicted, of which 32 were expressed in 7 DAP library and 78 were expressed in 14 DAP library (Table 4). The minimum free energy of pre-miRNAs ranged from $-187.00 \mathrm{kcal} \mathrm{mol}^{-1}$ to $-37.40 \mathrm{kcal}^{-1}$ $\mathrm{mol}^{-1}$, with an average of about $-96.83 \mathrm{kcal} \mathrm{mol}^{-1}$. This indicates the high stability of hairpin structures. Detailed information of all the novel miRNAs is provided in Additional file 4, and the secondary structures of the novel pre-miRNAs are shown in Additional file 5 and Fig. 4.

More novel miRNAs were expressed in 14 DAP than in 7 DAP, and 31 novel miRNAs were commonly expressed in two libraries, with 1 special in 7 DAP library and 47 specials in 14 DAP library. Majority of novel miRNAs presented a relatively low expression level. The most abundant novel miRNAs were novel-m0064_5p, novel-m0492_5p and novel-m0661_5p (Additional file 4).

\section{Degradome sequencing and data summary}

After RNA was extracted and poly (A+) RNA was purified from the developing wheat grains at 7 DAP and 14 DAP, a degradome library was constructed and subsequently subjected to degradome sequencing. A total of 10,620,205 clean reads and 4,612,965 unique reads were obtained (Table 5). A total of 2,776,485 (60.19\%) unique reads were matched to the reference genome. Using BLASTN search against GenBank and Rfam databases, the structural RNAs (rRNAs, tRNAs, snRNAs, and snoRNAs) were removed, and the remaining reads were used to detect candidate targets of miRNAs.

Degradome analysis could provide experimental evidence for miRNA-mediated cleavage of target transcripts, so the target genes of miRNAs were analyzed by degradome sequencing. The results showed that 23 targets were predicted to be cleaved by 7 miRNAs, including 3 known and 4 novel miRNAs. The known miRNAs were tae-miR156, tae-miR160 and tae-miR1119, and the novel miRNA were novel-miR0011, novel-miR0012, novel-miR0036 and novel-miR0075 (Table 6, Additional file 6). Furthermore, most miRNAs potentially regulated multiple targets whereas some miRNAs only acted on one target gene. Tae-miR160 repressed five target genes including Traes_1AL_147CF243C, Traes_1BL_54CD82AC3, Traes_7AL_E3ADC8C38, Traes_7BL_18D335F08 and Traes_7DL_55ADB3528; tae-miR1119 acted on three targets including Traes_6BS_04A3400AF, Traes_6BS_222CE7DA7 and Traes_6BS_4D03398A8; novel-miR0012 targeted Traes_3DS_2F5F2C276, Traes_3B_8824DBB56 and Traes_3AS_7EEF1386F, and novel-miR0011 targeted Traes_3DS_C6D17D438 and Traes_3B_E7D2E8720. Moreover, novel-miR0036, novel-miR0075 and taemiR156 targeted Traes_7AS_2084DE83B, Traes_5AL_147EA9565 and Traes_6BS_542961EA4, respectively. Of the 16 targets, 13 of them have functional annotations (Table 6, Fig. 5).

\section{Differentially expressed miRNAs between 7 DAP and 14 DAP grains}

To identify miRNAs associated with early wheat grain development, the differentially expressed miRNAs were analyzed based on the statistical method reported by Audic and Claverie [42]. A total of 19 known and 20 novel miRNAs were differentially expressed 
$(P<0.05)$ between the 7 DAP and 14 DAP grains, and 18 known miRNAs and 13 novel miRNAs were up-regulated in 14 DAP grains (Additional file 7).

To verify the miRNA expression levels and the deep-sequencing results, eight known and two novel miRNAs were randomly selected for quantitative real-time polymerase chain reaction (qRT-PCR). The results showed that the expression patterns of these miRNAs were consistent with those from deep-sequencing, which indicated that our sRNA sequencing was credible (Fig. 6).

\section{Functions of miRNA targets}

To understand the functions of miRNAs in the regulatory network of early wheat grain development, miRNA target genes were analyzed across small RNA and degradome libraries. A total of 266 targets for 40 known wheat miRNAs, 152 targets for 13 other known plant miRNAs and 258 targets for 25 novel miRNAs were predicted (Additional file 8).

Functional annotations for the target genes of differentially expressed miRNA were performed by BLAST analysis, and it was found that the targets included those genes encoding mitogen-activated protein kinase, transcription factor GAMYB, WRKY transcription factor 33, F-box/kelch-repeat protein, transcription factor PCF6, NAC domain-containing protein, ethylene-responsive transcription factor, SPX domain-containing protein, vegetative cell wall protein gp1, extensin precursor, cytokinin dehydrogenase 5, calciumdependent protein kinase and squamosa promoter-binding-like protein (SPL), etc. (Additional file 9).

GO analysis revealed that some targets of differentially expressed miRNAs were involved in biological processes such as mitotic cell cycle (GO:0000278), nuclear division (G0:0000280), cell morphogenesis (G0:0000902), seed development (G0:0048316), embryo development (G0:0009790) (4 targets for 2 miRNAs), meristem initiation (GO:0010014), carpel development (G0:0048440), cell differentiation (GO:0030154), cell division (G0:0051301), starch metabolic process (GO:0005982) and regulation of cell division (G0:0051302). These results imply that some of these differentially expressed miRNAs were involved in regulating grain development.

GO analysis of the differentially expressed miRNAs between 7 DAP and 14 DAP grains was applied to classify their target genes according to their cellular component, molecular function, and biological processes. A total of 10 molecular functions were identified, of which binding, catalytic activity, and nucleic acid transcription factor activity were the three most frequent functions. For biological processes, 20 categories were identified, of which cellular processes, metabolic processes and single organism processes were the three most frequent ones. For the cellular component, 11 categories were identified, of which cell part, cell and organelle were the three most frequent processes (Additional file 9, Fig. 7).

Furthermore, gene-specific qRT-PCR was performed to detected the expression levels of potential targets. The 8 target genes of 8 miRNAs (five known and three novel) were selected randomly. The expression analysis indicated that the target genes were negatively correlated with the expression of their corresponding miRNAs (Fig. 8). These results suggest that miRNAs are involved in the developmental processes of wheat grains by regulating their target genes expression.

\section{Discussion}

It is known that miRNAs are involved in diverse developmental processes. Previous studies have showed that miRNAs were associated with development and stress response in wheat. Here, we investigated the miRNAs and their targets to find the association between miRNAs and early grain development of wheat, which is one of the most important crops for human foods.

In this study, 105 known and 79 novel miRNAs were identified from two libraries of grains at 7 DAP and 14DAP. Expression analysis showed that 19 known and 20 novel miRNAs were differentially expressed, and 18 known and 13 novel miRNAs were up-regulated at 14 DAP. During rice grain development, most miRNAs showed increased expression from 5 to 10 DAP [26]. A few researches have been reported in wheat. Most of the differentially expressed miRNAs were up-regulated with grain and leaf development; only little parts were down-regulated $[27,40]$. These results suggest that most miRNAs were highly expressed during organ development in crops.

Of the differentially expressed known miRNAs, miR156 was up-regulated at 14 DAP compared to 7 DAP in the present study. Pioneering research showed that miR156 directly repressed the expression of SPL transcription factor genes that play an important 
role in plant growth and development [43]. In rice, OsSPL16 controls grain size, shape and quality [44], and OsSPL13 positively regulates the cell size of grain hull and then controls grain size [45]. TaSPL 16, a target of miR156 in wheat, is highly expressed in developing young panicles, and lowly expressed in developing grains [46], because the expression level of miR156 was up-regulated with the development of wheat grain. Therefore, miR156 may well play an important role in regulating wheat grain development.

It has been reported that miR164 targets NAC (NAM, ATAF, and $C U C)$ transcription factor genes that play major roles in the proper formation and separation of plant organs [47], auxin signaling and defense [48]. Auxin is crucial during the grain/seed development, including pattern formation, cell division and cell expansion [49]. In wheat grain, NAC genes regulating senescence have the functions to improve protein, zinc and iron contents [50]. In this study, miR164 is up-regulated from 7 DAP to 14 DAP grains. It is also shown that miR164 increased in abundance from 5 DAP to 20 DAP [27]. Furthermore, NAC transcription factors were predicted to be involved in regulating the timing of organ formation (G0:0048504), negative regulation of cell division, regulation of cell size, response to temperature stimulus and light stimulus (Additional file 9). It may be that miR164 takes part in the regulation of early wheat grain development.

MiR319 (bdi-miR319b-3p, tae-miR319) targeted TCP (TEOSINTE BRANCHED 1, CYCLOIDEA and PCF) transcription factor genes in Arabidopsis thaliana. And the research showed that TCP 3 regulated the activities of miR164 during the differentiation of leaves in Arabidopsis [51]. In our study, the miR319 was down-regulated at 14 DAP, perhaps with the target up-regulated. The target in turn regulated miR164 expression. And we predict that the targets of miR319 are involved in negative regulation of cell proliferation and differentiation, positive regulation of ovule development (G0:0048481), mucilage biosynthesis involved in seed coat development, response to auxin and abscisic acid, response to gibberellin, jasmonic acid-mediated signaling pathway and ethylene-activated signaling pathway (Additional file 9). A putative miRNA regulatory network in wheat grains showed that miR156, miR164, miR319 and miR396 play a role in cell proliferation [40]. In the present study, however, miR396 showed no difference during the early development of wheat grains.

MiR167 targets ARF (AUXIN RESPONSE FACTOR) transcription factor genes, which play critical roles in regulating plant growth and development [52], ARF8 is a negative regulator of fruit initiation in Arabidopsis [53]. In this study, miR167 is up-regulated from 7 DAP to 14 DAP. In previous research, it was up-regulated from 5 DAP to 15 DAP [1], 7DAP to 14 DAP and down-regulated from 14 DAP to 28 DAP in wheat grain [40]. These results showed that MiR167 is important in wheat grain development. Research showed that $A R F$ members are targeted by miR164, whereas many TFs such as TCP members are the regulators of miR167 [54], indicating mutual regulation between TFs and miRNAs.

Known miRNA such as tae-miR7757-5p targets the genes encoding WRKY DNA-binding domain and NB-ARC domain-containing proteins involved in jasmonic acid-mediated signaling pathway, regulation of plant-type hypersensitive response, response to hydrogen peroxide, and regulation of multi-organism process. MiR9662 (tae-miR9662a-3p, tae-miR9662b-3p) targets the genes related to vegetative cell wall protein, protein kinase activity (GO:0004672), protein phosphorylation (G0:0006468), plant-type cell wall organization (G0:0009664), multicellular organismal process (G0:0032501), and regulation of cellular process (G0:0050794)

(Additional file 9). This shows the extensive effects of miRNAs in early wheat grain development and might participate in regulating wheat grain development and metabolism. Previous reports indicated that tae-miR1127b was important for early grain development and played a crucial role in the uptake of amino acids into the endosperm [27].

MiR156, miR164, miR319 and miR167 were differentially expressed in developing grains, as found in previous studies. However, some miRNAs, such as miR159 and miR396 targeting the growth-regulating factors (GRFs), were expressed at the same level in 7 DAP and 14 DAP grains. In previous research, miR396 was under-expressed and miR159 was over-expressed from 7 DAP to 14 DAP. They were predicted to target the mRNA of a GAMYB-like transcription factor gene involved in gibberellin signaling and plant anther development [40]. We guess that some miRNAs presented adaptive expression levels under different genetic backgrounds and environmental conditions.

The novel-miR0018 targets WRKY transcription factor genes. Previous research postulated that WRKY23 participated in the regulation of plant stem cell specification via auxin-dependent or auxin-independent signaling pathway [55]. WRKY23 could regulate auxin distribution patterns through controlling flavonol biosynthesis during Arabidopsis root development [56]. Perhaps novel-miR0018 plays important roles during the development of early wheat grain. 
The novel-miR0019 targets MADS-box transcription factor genes. The MADS-domain regulator AGAMOUS-like 15 (AGL15) could enhance somatic embryo development in Arabidopsis and soybean while ectopically expressed [57], and AGL15 was accumulated to its highest amount during embryo development [58]. Meanwhile, we found that novel-miR0019 targeted the genes related to cytokinin biosynthetic process, plant-type cell wall modification, post-embryonic morphogenesis, organ morphogenesis (G0:0009887), seed development (G0:0048316), ovule development (G0:0048481) and meristem development (G0:0048507).

The novel-miR0036 was significantly down-regulated at 14 DAP compared to 7 DAP (Additional file 7), and it was predicted to target DHHC palmitoyl transferase gene. DHHC proteins regulated cell function and influenced cell physiology and pathophysiology [59], indicating that novel-miR0036 played an important role during wheat grain development. And other novel miRNAs target the genes that are involved in lipid transport and metabolism (novel miR0005), signal transduction mechanisms (novel miR0079), posttranslational modification (novel miR0078), chromatin structure and carbohydrate transport (novel miR0034, novel miR0070), ribosomal structure and biogenesis (novel miR0075), replication, recombination and repair (novel miR0031) (Additional file 9). Perhaps these novel miRNAs widely participate in the regulations of early wheat grain development and metabolism.

\section{Conclusion}

This study suggests that quite a few known and novel miRNAs and their targets play extensive roles during the early grain development of common wheat. Understanding of miRNA-mediated regulatory network involved in wheat grain development will help us to elucidate the molecular mechanisms underlying wheat grain development and carry out ingenious molecular improvements in wheat breeding.

\section{Methods}

\section{Plant materials and sample preparation}

The experiments were performed using the 7DAP and 14DAP grains of common wheat cultivar "Bainong 4199" (Triticum aestivum L.) bred and friendly provided by the Centre for Wheat Breeding, Henan Institute of Science and Technology. "Bainong 4199" is a high yield cultivar with plump grain and is widely planted in China. Seeds of "Bainong 4199" were firstly soaked in the tap water for $24 \mathrm{~h}$, then disposed in $4^{\circ} \mathrm{C}$ dark chamber for one month. After vernalization, they were planted in the greenhouse maintaining $75 \%$ relative humidity, $26 / 20^{\circ} \mathrm{C}$ day/night temperature, 12 -h light/dark photoperiod, and 10,000 lux light intensity. Day of pollination was recorded when half of the plants reached the flowering stage. For volume and fresh weight measurements, immature grains were collected for every 3-5 days, starting from 5 DAP to 34 DAP. And the grains were collected from the middle four rows of spikes at 7 and 14 DAP for deep sequencing and miRNAs analysis. Three biological replicates were made, and each consists of 100 grains. All samples were snap-frozen in liquid nitrogen and stored at $-80^{\circ} \mathrm{C}$ for subsequent experiments.

\section{Small RNA and Degradome Sequencing}

Total RNAs were isolated using TRIzol reagent (Invitrogen, Carlsbad, CA, USA) according to the manufacturer's instructions. Qualified RNA samples must meet the conditions of OD260/280 $=1.8-2.2$ and RNA integrity number $>8.0$. RNA samples in three biological replicates were equally mixed to get respective RNA pool of 7 DAP and 14 DAP grains. These two RNA pools were used to construct small libraries by TruSeq Small RNA Library Prep Kit (Illumina, USA), according to the manufacturer's protocols. In brief, $700-\mu \mathrm{g}$ RNA sample of each RNA pool was firstly fractionated on a $15 \%$ denaturing polyacrylamide gel, then the sRNAs with 18-30 nt were recovered. The $5^{\prime}$ and $3^{\prime}$ RNA adapters were ligated to the $5^{\prime}$ and $3^{\prime}$ ends of these sRNAs using T4 RNA ligase (Takara, Dalian, China). Purified ligation products were converted to CDNAs, which were used to construct the cDNA tag libraries by RT-PCR amplification. The size, purity and concentration of cDNA tag libraries were detected using an Agilent2100 Bioanalyzer (Agilent Technologies, Santa Clara, CA, USA). The cDNA tag libraries were sequenced using a HiSeq ${ }^{\text {TM }} 2000$ Sequencing System (IIlumina, San Diego, CA, USA), according to the manufacturer's instructions.

The samples for miRNA sequencing were used to construct the degradome libraries. Degradome libraries were constructed by ligating polyA-enriched RNAs to the custom RNA adapter containing a 3' Mmel site. This is followed by reverse transcription, second-strand synthesis, Mme I digestion, ligation of 3' dsDNA adapter, gel-purification and PCR amplification. Amplified degradome tag libraries were then sequenced using a Solexa/Illumina genome analyzer [60]. 


\section{MiRNAs identification and expression analysis}

The reads from cDNA tag libraries sequencing were processed by Phred and Crossmatch (http://www.phrap.org/phredphrapconsed.html) [61]. Clean reads were obtained after low-quality reads and adapter sequences were removed. The 18-30 nt clean reads (tags) were matched to the sequences of Rfam [62], GenBank, and RepBase [63] databases to distinguish rRNA, scRNA, snoRNA, snRNA and tRNA from clean reads. After those reads having more than $90 \%$ sequence similarity to above RNAs were removed, the remaining sequences were matched to wheat expressed sequence tag (EST) database (http://www.ncbi.nlm.nih.gov/nucest/?term=wheat) or wheat genome sequences (http://mips.helmholtzmuenchen.de/plant/wheat/uk454survey/index.jsp) [64]. Ultimately, the non-coding tags were used to identify the candidate miRNAs.

Known miRNAs and novel miRNAs were identified from above non-coding tags referring to the methods reported by Chu et al. [31], with some modifications. In brief, the non-coding tags were firstly matched to the sequences of miRBase 22.0, the perfectly matched tags were the known miRNAs, and the others were used to predict novel miRNAs. The predicted miRNAs should have the potential forming a hairpin secondary structure when analyzed using RNAfold (http://rna.tbi.univie.ac.at/cgi-bin/RNAfold.cgi) [65].

For eliminating the disturbing of gene length and sequencing deep to the count of miRNA actual expression level, the frequency of each read count was firstly normalized according to the formula TPMi $=(\mathrm{Ni} / \mathrm{Li}) \times 1,000,000 / \mathrm{sum}(\mathrm{Ni} / \mathrm{Li}+\ldots \ldots . .+\mathrm{Nm} / \mathrm{Lm})$; $\mathrm{Ni}$ is the number of reads mapped to gene $i$, and $L i$ is the length sum of the exons of gene $i$. The fold-change of miRNA expression between the 14 DAP and 7DAP libraries was calculated as $\log _{2}$ (14DAP/7DAP). If the $P$-value was $\leq 0.01$ and the normalized sequence count had a fold change of $>2$ or $<0.5$, the given miRNA was recognized to be differentially expressed.

\section{MiRNA target annotation}

Prediction and annotation of miRNA targets were performed as the methods reported by Chu et al. [31]. Identified miRNAs were aligned against wheat sequence databases. MiRNA targets were predicted according to the TargetFinder

(https://github.com/carringtonlab/TargetFinder?). BLASTN hits with less than four mismatches were chosen as candidate targets; for the non-target predicted miRNA, the psRNATarget software (http://plantgrn.noble.org/psRNATarget/) (version 12) was used to predict the targets in wheat transcripts with prediction score cutoff value $=3.0$, length for complementarity scoring $=20$, and target accessibility $=25$.

For the degradome sequencing data, 20-21 nt sequences of high quality were collected for subsequent analysis. The unique reads that perfectly matched wheat expressed sequence tag (EST) database from NCBI or the contig sequences from WGS assembly were retained. Approximately $15 \mathrm{nt}$ upstream and downstream of 5 ' wheat EST sequences, mapped by degradome reads, were extracted to generate $31 \mathrm{nt}$ target signatures as 't-signatures' [66]. The CleaveL and pipeline were used to identify miRNA targets [60]. Alignments with scores up to four where $\mathrm{G}: U$ pairs scored 0.5 and no mismatches were found at the site between the 10 th and 11th nucleotides of the corresponding miRNAs were considered potential targets. Consistent mRNAs obtained from both methods were chosen as miRNA targets. To understand their functions, the putative target genes of the miRNAs were BLASTX and subjected to $\mathrm{GO}$ analysis.

\section{MiRNA and Target validation by real-time PCR}

QRT-PCR was performed to determine the validities of RNA Seq and target analysis. A total of 10 miRNAs and 8 target genes were selected randomly. RNA was extracted from three independent biological samples of 7DAP and 14DAP grains, individually, and used for transcription (RT) reactions. The One Step Primer Script miRNA cDNA Synthesis Kit (Takara) and PrimeScript ${ }^{\circledR}$ RT reagent Kit with gDNA Eraser (Perfect Real Time; Takara) were used for the RT reactions of miRNAs and targets following the manufacturer's instructions, respectively. RT-PCR was performed using a Bio-Rad IQ5 Real-Time PCR Detection System (BIO-RAD, Hercules, CA, USA) with SYBR® Premix Ex Taq II ${ }^{\text {TM }}$ (Takara). The total volume of each reaction is $25 \mu \mathrm{L}[2.0 \mu \mathrm{L}$ of diluted product, $2.0 \mu \mathrm{L}$ of primers, $12.5 \mu \mathrm{L}$ of SYBR® Premix Ex Taq ${ }^{\mathrm{TM}}$ (Perfect Real Time; Takara), and $8.5 \mu \mathrm{L}$ of nuclease-free water]. All reactions were performed firstly at $95^{\circ} \mathrm{C}$ for $30 \mathrm{~s}$, then followed by 40 cycles $\left(95^{\circ} \mathrm{C}\right.$ for $5 \mathrm{~s}, 61^{\circ} \mathrm{C}$ for $30 \mathrm{~s}$, and $72{ }^{\circ} \mathrm{C}$ for $30 \mathrm{~s}$ ). All reactions were performed three times. 
Wheat U6 [GenBank: X63066] snRNA and the actin gene (GenBank: AB181991) were used as the endogenous control for miRNAs and target genes. The relative abundance of each miRNA was calculated by a comparative $\mathrm{C}_{\mathrm{T}}$ method $\left(\Delta \Delta \mathrm{C}_{\mathrm{T}}\right)$ using the formula $2^{-}$

$\Delta \Delta C_{T}$ [67]. The miRNAs and target samples in the 0 DAP library with the $C_{\mathrm{T}}$ value were selected as the calibrator, and the expression level was set as 1.0. The relative expression levels of the same miRNAs and targets were normalized through comparison. All primers used in this study are presented in Additional file 10.

\section{Abbreviations}

sRNAs: Small RNAs; miRNAs: microRNAs; DAP: Days after pollination; qRT-PCR: Quantitative real-time polymerase chain reaction; GO: Gene ontology; COG: Cluster of orthologous groups; ARF: Auxin-responsive factor; SBP: SQUAMOSA promoter-binding protein; SPL: SQUAMOSA promoter-binding protein-like

\section{Declarations}

\section{Ethics approval and consent to participate}

Not applicable.

\section{Consent to publish}

Not applicable.

\section{Availability of data and materials}

The datasets used and/or analyzed during the current study are available from the Additional files or corresponding author on reasonable request.

\section{Competing interests}

The authors declare that they have no competing interests.

\section{Funding}

This work was supported by grants 31371664, 2018YFD0200601 and 182300410002 from the National Natural Science Foundation of China, the National Key Research and Development Program of China, and the Key Project of Henan Natural Science Foundation. The funders had no role in the experiment design, data analysis, decision to publish, or preparation of the manuscript.

\section{Authors' contributions}

WW and ML: designed and executed this study. QC, LX and ZAB: performed experiments and wrote the main manuscript text. YG: performed and designed computational analysis. GL: prepared the experimental materials. GZ and CL: performed experiments and prepared figures. JH: discussed the results. All authors have read and approved the final version of the manuscript.

\section{Acknowledgements}

The authors thank Dr. Zongli Chu for assisting data analyzing and M.S. Zhaopu Wen for assisting qRT-PCR experiment, respectively.

\section{References}

1. Meng F, Liu H, Wang K, Liu L, Wang S, Zhao Y, Yin J, Li Y. Development-associated microRNAs in grains of wheat (Triticum aestivum). BMC Plant Biol. 2013; 13(1):140.

2. Xie Q, Mayes S, Sparkes DL. Carpel size, grain filling, and morphology determine individual grain weight in wheat. J Exp Bot. $2015 ; 66(21): 6715-6730$. 
3. Millet E, Pinthus MJ. The association between grain volume and grain weight in wheat. J Cereal Sci. 1984; 2(1):31-35.

4. Lizana XC, Riegel R, Gomez LD, Herrera J, Isla A, McQueen-Mason SJ, Calderini DF. Expansins expression is associated with grain size dynamics in wheat (Triticum aestivum). J Exp Bot. 2010; 61(4):1147-1157.

5. Sabelli PA, Larkins BA. The development of endosperm in grasses. Plant Physiol. 2009; 149(1):14-26.

6. Abdipour M, Ebrahimi M, Izadi-Darbandi A, Mastrangelo AM, Najafian G, Arshad Y, Mirniyam G. Association between grain size and shape and quality traits, and path analysis of thousand grain weight in Iranian bread wheat landraces from different geographic regions. Not Bot Horti Agrobo. 2016; 44(1):228-236.

7. Zanke CD, Ling J, Plieske J, Kollers S, Ebmeyer E, Korzun V, Argillier O, Stiewe G, Hinze M, Neumann F. Analysis of main effect QTL for thousand grain weight in European winter wheat (Triticum aestivum L.) by genome-wide association mapping. Front Plant Sci. 2015; 6(644):644.

8. Baillot N, Girousse C, Allard V, Piquet-Pissaloux A, Le Gouis J. Different grain-filling rates explain grain-weight differences along the wheat PLoS One. 2018; 13(12):e0209597.

9. Jonesrhoades MW, Bartel DP, Bartel B. MicroRNAS and their regulatory roles in plants. Annu Rev Plant Biol. 2006; 57(1):19-53.

10. Axtell MJ, Westholm JO, Lai EC. Vive la différence: biogenesis and evolution of microRNAs in plants and animals. Genome Biol. 2011; 12(4):221.

11. Lee Y, Kim M, Han J, Yeom KH, Lee S, Baek SH, Kim VN. MicroRNA genes are transcribed by RNA polymerase II. EMBO J. 2004; 23(20):4051-4060.

12. Kim VN. MicroRNA biogenesis: coordinated cropping and dicing. Nature Reviews Mol Cell Biol. 2005; 6(5):376-385.

13. Voinnet O. Origin, biogenesis, and activity of plant microRNAs. 2009; 136(4):669-687.

14. Monga I, Kumar M. Computational resources for prediction and analysis of functional miRNA and their $t$ Methods Mol Biol. 2019; 1912:215-250.

15. Yu X, Wang H, Lu Y, De Ruiter M, Cariaso M, Prins M, Van Tunen A, He Y. Identification of conserved and novel microRNAs that are responsive to heat stress in Brassica rapa. J Exp Bot. 2012; 63(2):1025-1038.

16. Tang Z, Zhang L, Xu C, Yuan S, Zhang F, Zheng Y, Zhao C. Uncovering small RNA-mediated responses to cold stress in a wheat thermosensitive genic male-sterile line by deep sequencing. Plant Physiol. 2012; 159(2):721-738.

17. Li G, Wang Y, Lou X, Li H, Zhang C. Identification of blueberry miRNAs and their targets based on high-throughput sequencing and degradome a Int J Mol Sci. 2018; 19(4):983.

18. Cuperus JT, Fahlgren N, Carrington JC. Evolution and functional diversification of MIRNA genes. Plant Cell. 2011; 23(2):431442.

19. D'Ario M, Griffithsjones S, Kim M. Small RNAs: big impact on plant development. Trends Plant Sci. 2017; 22(12):1056.

20. Sanz-Carbonell A, Marques MC, Bustamante A, Fares MA, Rodrigo G, Gomez Inferring the regulatory network of the miRNAmediated response to biotic and abiotic stress in melon. BMC Plant Biol. 2019; $19(1): 78$.

21. Yao X, Chen J, Zhou J, Yu H, Ge C, Zhang M, Gao X, Dai X, Yang ZN, Zhao Y. An essential role for miRNA167 in maternal control of embryonic and seed d Plant Physiol. 2019; 180(1):453-464.

22. Zheng L, Zhang X, Zhang H, Gu Y, Huang X, Huang H, Liu H, Zhang J, Hu Y, Li Y, Yu G, Liu Y, Lawson SS, Huang Y. The miR164dependent regulatory pathway in developing maize seed. Mol Genet Genomics. 2019; 294(2):501-517.

23. Peng T, Sun H, Qiao M, Zhao Y, Du Y, Zhang J, Li J, Tang G, Zhao Q. Differentially expressed microRNA cohorts in seed development may contribute to poor grain filling of inferior spikelets in rice. BMC Plant Biol. 2014; 14:196.

24. Bai B, Shi B, Hou N, Cao Y, Meng Y, Bian H, Zhu M, Han N. MicroRNAs participate in gene expression regulation and phytohormone cross-talk in barley embryo during seed development and germination. BMC Plant Biol. 2017; 17(1):150.

25. Wei WH, Li G, Jiang XL, Wang YQ, Ma ZH, Niu ZP, Wang ZW, Geng XX. Small RNA and degradome profiling involved in seed development and oil synthesis of Brassica napus. PLoS One. 2018; 13(10):e0204998.

26. Zhu QH, Spriggs A, Matthew L, Fan L, Kennedy G, Gubler F, Helliwell C. A diverse set of microRNAs and microRNA-like small RNAs in developing rice grains. Genome Res. 2008; 18(9):1456-1465.

27. Han R, Jian C, Lv J, Yan Y, Chi Q, Li Z, Wang Q, Zhang J, Liu X, Zhao H. Identification and characterization of microRNAs in the flag leaf and developing seed of wheat (Triticum aestivum). BMC Genomics. 2014; 15(1):289.

Page 10/29 
28. Zhang YC, Yu Y, Wang CY, Li ZY, Liu Q, Xu J, Liao JY, Wang XJ, Qu LH, Chen F. Overexpression of microRNA OsmiR397 improves rice yield by increasing grain size and promoting panicle branching. Nature Biotech. 2013; 31(9):848.

29. Li YF, Zheng Y, Jagadeeswaran G, Sunkar R. Characterization of small RNAs and their target genes in wheat seedlings using sequencing-based approaches. Plant Sci. 2013; 203-204(2):17-24.

30. Mueth NA, Ramachandran SR, Hulbert SH. Small RNAs from the wheat stripe rust fungus (Puccinia striiformissp. tritici). BMC Genomics. 2015; 16(1):718.

31. Chu Z, Chen J, Xu H, Dong Z, Feng C, Cui D. Identification and comparative analysis of microRNA in wheat (Triticum aestivum) callus derived from mature and immature embryos during in vitro culture. Front Plant Sci. 2016; 7(1119).

32. Sun F, Guo G, Du J, Guo W, Peng H, Ni Z, Sun Q, Yao Y. Whole-genome discovery of miRNAs and their targets in wheat (Triticum aestivum). BMC Plant Biol. 2014; 14(1):142.

33. Kurtoglu KY, Kantar M, Budak H. New wheat microRNA using whole-genome sequence. Funct Integr Genomic. 2014; 14(2):363379.

34. Yao Y, Sun Q. Exploration of small non coding RNAs in wheat (Triticum aestivum). Plant Mol Biol. 2012; 80(1):67-73.

35. Xin MM, Wang Y, Yao YY, Xie CJ, Peng HR, Ni ZF, Sun QX. Diverse set of microRNAs are responsive to powdery mildew infection and heat stress in wheat (Triticum aestivum). BMC Plant Biol. 2010; 10(1):123.

36. Pantaleo V, Szittya G, Moxon S, Miozzi L, Moulton V, Dalmay T, Burgyan J. Identification of grapevine microRNAs and their targets using high-throughput sequencing and degradome analysis. Plant J. 2010; 62(6):960-976.

37. Yang X, Wang L, Yuan D, Lindsey K, Zhang X. Small RNA and degradome sequencing reveal complex miRNA regulation during cotton somatic embryogenesis. J Exp Bot. 2013; 64(6):1521-1536.

38. Jin X, Jia L, Wang Y, Li B, Sun D, Chen X. Identification of Fusarium graminearum-responsive miRNAs and their targets in wheat by sRNA sequencing and degradome Funct Integr Genomic. 2020; 20(1):51-61.

39. Chen F, Zhang X, Zhang N, Wang S, Yin G, Dong Z, Cui D. Combined small RNA and degradome sequencing reveals novel miRNAs and their targets in the high-yield mutant wheat strain Yunong 3114. Plos One. 2015; 10(9):e0137773.

40. Li T, Ma L, Geng Y, Hao C, Chen X, Zhang X. Small RNA and degradome sequencing reveal complex roles of miRNAs and their targets in developing wheat grains. Plos One. 2015; 10(10):e0139658.

41. Meyers BC, Axtell MJ, Bartel B, Bartel DP, Baulcombe D, Bowman JL, Cao X, Carrington JC, Chen X, Green PJ et al. Criteria for annotation of plant microRNAs. Plant Cell. 2008; 20(12):3186-3190.

42. Audic S, Claverie JM. The significance of digital gene expression profiles. Genome Res. 1997; 7(10):986-95.

43. Wang JW, Czech B, Weigel D. MiR156-regulated SPL transcription factors define an endogenous flowering pathway in Arabidopsis thaliana. 2009; 138(4):738-749.

44. Wang S, Wu K, Yuan Q, Liu X, Liu Z, Lin X, Zeng R, Zhu H, Dong G, Qian Q, Zhang G, Fu X. Control of grain size, shape and quality by OsSPL16 in rice. Nature Genet. 2012; 44(8):950-954.

45. Si L, Chen J, Huang X, Gong H, Luo J, Hou Q, Zhou T, Lu T, Zhu J, Shangguan Y et al.. OsSPL13 controls grain size in cultivated rice. Nature Genet. 2016; 48(4):447-456.

46. Cao RF, Guo LJ, Ma M, Zhang WJ, Liu XL, Zhao Identification and functional characterization of squamosapromoter binding protein-like gene TaSPL 16 in wheat ( Triticum aestivum L.). Front Plant Sci. 2019; 10:212.

47. Mallory AC, Dugas DV, Bartel DP, Bartel B. MicroRNA regulation of NAC-domain targets is required for proper formation and separation of adjacent embryonic, vegetative, and floral organs. Current Biol. 2004; 14(12):1035-1046.

48. Olsen, Nina A, Ernst, Heidi A, Leggio, Lo L, Skriver, Karen. NAC transcription factors: structurally distinct, functionally diverse. Trends Plant Sci. 2005; 10(2):79-87.

49. Schruff MC, Spielman M, Tiwari S, Adams S, Fenby N, Scott RJ. The AUXIN RESPONSE FACTOR 2 gene of Arabidopsis links auxin signalling, cell division, and the size of seeds and other organs. 2006; 133(2):251-261.

50. Uauy C, Distelfeld A, Fahima T, Blechl A, Dubcovsky J. A NAC gene regulating senescence improves grain protein, zinc, and iron content in wheat. 2006; 314(5803):1298-1301.

51. Koyama T, Mitsuda N, Seki M, Shinozaki K, Ohme-Takagi M. TCP transcription factors regulate the activities of ASYMMETRIC LEAVES1 and miR164, as well as the auxin response, during differentiation of leaves in Arabidopsis. Plant Cell. 2010;

Page 11/29 
22(11):3574.

52. Ru P, Xu L, Ma H, Huang H. Plant fertility defects induced by the enhanced expression of microRNA167. Cell Res. 2006; 16(5):457-465.

53. Goetz M, Vivian-Smith A, Johnson SD, Koltunow AM. AUXIN RESPONSE FACTOR8 is a negative regulator of fruit initiation in Arabidopsis. Plant Cell. 2006; 18(8):1873-1886.

54. Phookaew P, Netrphan S, Sojikul P, Narangajavana J. Involvement of miR164- and miR167-mediated target gene expressions in responses to water deficit in Cassava. Biologia Plantarum. 2014; 469-478.

55. Grunewald W, De SI, De RB, Robert HS, Van dCB, Willemsen V, Gheysen G, Weijers D, Friml J, Beeckman T. Tightly controlled WRKY23 expression mediates Arabidopsis embryo development. EMBO Report. 2013; 14(12):1136-1142.

56. Grunewald W, Smet ID, Lewis DR, Löfke C, Jansen L, Goeminne G, Bossche RV, Karimi M, Rybel BD, Vanholme B. Transcription factor WRKY23 assists auxin distribution patterns during Arabidopsis root development through local control on flavonol biosynthesis. Proc Natl Acad Sci USA. 2012; 109(5):1554-1559.

57. Thakare D, Tang W, Hill K, Perry SE. The MADS-domain transcriptional regulator AGAMOUS-LIKE15 promotes somatic embryo development in Arabidopsis and soybean. Plant Physiol. 2008; 146(4):1663-1672.

58. Wang H, Caruso LV, Downie AB, Perry SE. The embryo MADS domain protein AGAMOUS-Like 15 directly regulates expression of a gene encoding an enzyme involved in gibberellin metabolism. Plant Cell. 2004; 16(5):1206-1219.

59. Greaves J, Chamberlain LH. DHHC palmitoyl transferases: substrate interactions and (patho) physiology. Trends Biochem Sci. $2011 ; 36(5): 245-253$.

60. Addo-Quaye C, Eshoo TW, Bartel DP, Axtell MJ. Endogenous siRNA and miRNA targets identified by sequencing of the Arabidopsis degradome. Current Biol. 2008; 18(10): 758-762.

61. Sunkar R, Zhu JK. Novel and stress-regulated microRNAs and other small RNAs from Arabidopsis. Plant Cell. 2004; 16(8):20012019.

62. Nawrocki EP, Burge SW, Bateman A, Daub J, Eberhardt RY, Eddy SR, Floden EW, Gardner PP, Jones TA, Tate J. Rfam 12.0: updates to the RNA families database. Nucleic Acids Res. 2015; 43(Database issue): D130.

63. Kapitonov VV, Jurka J. A universal classification of eukaryotic transposable elements implemented in Repbase. Nat Rev Genet. 2008; 9(5):411-412.

64. Brenchley R, Spannagl M, Pfeifer M, Barker GLA, D’Amore R, Allen AM, McKenzie N, Kramer M, Kerhornou A, Bolser D. Analysis of the bread wheat genome using whole-genome shotgun sequencing. 2012; 491(7426):705-710.

65. Hofacker IL, Fontana W, Stadler PF, Bonhoeffer LS, Tacker M, Schuster P. Fast folding and comparison of RNA secondary structures. Monatshefte Für Chemie. 1994; 125(2):167-188.

66. German MA, Pillay M, Jeong DH, Hetawal A, Luo S, Janardhanan P, Kannan V, Rymarquis LA, Nobuta K, German R, De Paoli E, Lu C, Schroth G, Meyers BC, Green PJ. Global identification of microRNA-target RNA pairs by parallel analysis of RNA ends. Nature Biotech. 2008; 26(8):941-946.

67. Livak KJ, Schmittgen TD. Analysis of relative gene expression data using real-time quantitative PCR and the 2- $\triangle \Delta C T$ method. Methods-A Companion Meth Enzym. 2001; 25(4):402-408.

\section{Tables}

Table 1 Sequencing data of small RNA libraries derived from 7 DAP and 14 DAP grains

\begin{tabular}{|lllllll|}
\hline Samples & Raw_reads & Containing 'N' reads & Length<18 & Length>30 & Clean_reads & Q30(\%) \\
\hline 7 DAP & $22,900,708$ & 6,438 & $6,973,195$ & $1,900,391$ & $14,020,684$ & 93.5 \\
\hline 14 DAP & $20,279,914$ & 5,629 & $8,819,343$ & $1,075,938$ & $10,379,004$ & 93.6 \\
\hline
\end{tabular}

Table 2 Annotation and distribution of small RNAs in the libraries from 7DAP and 14DAP grains 


\begin{tabular}{|lllll|}
\hline 7 DAP clean & & & \multicolumn{3}{c|}{ 14 DAP clean } \\
\hline Types & Number & Percentage & Number & Percentage \\
\hline Total & $14,020,684$ & $100.00 \%$ & $10,379,004$ & $100.00 \%$ \\
\hline rRNA & $11,520,013$ & $82.16 \%$ & $6,364,460$ & $61.32 \%$ \\
\hline scRNA & 0 & $0.00 \%$ & 0 & $0.00 \%$ \\
\hline snRNA & 0 & $0.00 \%$ & 0 & $0.00 \%$ \\
\hline snoRNA & 4,476 & $0.03 \%$ & 30,967 & $0.30 \%$ \\
\hline tRNA & 171,402 & $1.22 \%$ & 556,108 & $5.36 \%$ \\
\hline Repbase & 4,011 & $0.03 \%$ & 39,747 & $0.38 \%$ \\
\hline Unannotated & $2,320,782$ & $16.56 \%$ & $3,387,722$ & $32.64 \%$ \\
\hline & & & & \\
\hline
\end{tabular}

Table 3 Sixteen known miRNAs from other plant species in two libraries 


\begin{tabular}{|c|c|c|c|c|c|c|}
\hline \multirow{2}{*}{$\begin{array}{l}\text { MiRNA } \\
\text { name }\end{array}$} & \multirow[t]{2}{*}{ MiRNA sequence } & \multirow[t]{2}{*}{ Genome ID } & \multirow{2}{*}{$\begin{array}{l}\text { Hairpin } \\
\text { energy }\end{array}$} & \multicolumn{2}{|l|}{ Abundance } & \multirow[t]{2}{*}{ Length } \\
\hline & & & & $7 \mathrm{DAP}$ & 14 DAP & \\
\hline $\begin{array}{l}\text { ata- } \\
\text { miR9863a- } \\
3 p\end{array}$ & ugagaagguagaucauaauagc & ta_iwgsc_1bs_v1_502147 & -76.9 & 28559.15826 & 44886.67326 & 22 \\
\hline $\begin{array}{l}\text { osa- } \\
\text { miR396e- } \\
5 p\end{array}$ & uccacaggcuuucuugaacug & ta_iwgsc_2bl_v1_7931332 & -96.6 & 10736.52566 & 18749.87386 & 21 \\
\hline $\begin{array}{l}\text { zma- } \\
\text { miR166n- } \\
3 p\end{array}$ & ucggaccaggcuucaaucccu & ta_iwgsc_5dl_v1_4522741 & -97 & 3650.418725 & 5308.091307 & 21 \\
\hline $\begin{array}{l}\text { osa- } \\
\text { miR166m }\end{array}$ & ucggaccaggcuucauucccu & ta_iwgsc_6dl_v1_3241952 & -112.2 & 2576.766158 & 1755.908531 & 21 \\
\hline $\begin{array}{l}\text { bdi- } \\
\text { miR319b- } \\
3 p\end{array}$ & uuggacugaagggugcucccu & ta_iwgsc_3b_v1_10469805 & -110.1 & 2147.305132 & 928.4114074 & 21 \\
\hline $\begin{array}{l}\text { zma- } \\
\text { miR396b- } \\
5 p\end{array}$ & uuccacagcuuucuugaacug & ta_iwgsc_6al_v1_5763211 & -105.7 & 1073.652566 & 1493.531394 & 21 \\
\hline $\begin{array}{l}\text { zma- } \\
\text { miR166a- } \\
3 p\end{array}$ & ucggaccaggcuucauucccc & ta_iwgsc_4dl_v3_14441658 & -84 & 1073.652566 & 1755.908531 & 21 \\
\hline $\begin{array}{l}\text { zma- } \\
\text { miR396f- } \\
5 p\end{array}$ & uuccacagcuuucuugaacuu & ta_iwgsc_6bl_v1_4250791 & -116.9 & 858.9220528 & 726.5828405 & 21 \\
\hline $\begin{array}{l}\text { bdi- } \\
\text { miR159a- } \\
3 p\end{array}$ & cuuggauugaagggagcucu & ta_iwgsc_7al_v1_4444449 & -112.8 & 644.1915396 & 1009.142834 & 20 \\
\hline $\begin{array}{l}\text { hbr- } \\
\text { miR166a }\end{array}$ & ucggaccaggcuucauucc & ta_iwgsc_6dl_v1_3241952 & -106.2 & 644.1915396 & 625.6685571 & 19 \\
\hline $\begin{array}{l}\text { gma- } \\
\text { miR167g }\end{array}$ & ugaagcugccagcaugaucuga & ta_iwgsc_4as_v2_5977836 & -101 & 644.1915396 & 5328.274164 & 22 \\
\hline $\begin{array}{l}\text { zma- } \\
\text { miR171n- } \\
3 p\end{array}$ & ugauugagccgcgccaauauc & ta_iwgsc_1bl_v1_3820936 & -73.3 & 644.1915396 & 666.0342705 & 21 \\
\hline $\begin{array}{l}\text { ata- } \\
\text { miR9674b- } \\
3 p\end{array}$ & ugaauuuguccauagcaucag & ta_iwgsc_3b_v1_10686187 & -101 & 214.7305132 & 867.8628373 & 21 \\
\hline $\begin{array}{l}\text { zma- } \\
\text { miR528b- } \\
5 p\end{array}$ & uggaaggggcaugcagaggag & ta_iwgsc_4bl_v1_6970925 & -93.6 & 0 & 666.0342705 & 21 \\
\hline $\begin{array}{l}\text { zma- } \\
\text { miR172e }\end{array}$ & ggaaucuugaugaugcugcau & ta_iwgsc_3b_v1_10649722 & -122.5 & 0 & 141.2799968 & 21 \\
\hline $\begin{array}{l}\text { ata- } \\
\text { miR393-5p }\end{array}$ & uuccaaagggaucgcauugau & ta_iwgsc_2al_v1_6315928 & -99.9 & 0 & 121.0971401 & 21 \\
\hline
\end{tabular}

Table 4 The number of known miRNAs, novel miRNAs and targets identified from 7 DAP and 14 DAP grains 


\begin{tabular}{|lllll|}
\hline Library & Known miRNAs & Known other miRNAs & Novel miRNAs & Total \\
\hline 7 DAP & 46 & 13 & 32 & 91 \\
\hline 14 DAP & 87 & 16 & 78 & 181 \\
\hline Total miRNAs & 89 & 16 & 79 & 184 \\
\hline MiRNAs with target & 41 & 13 & 25 & 79 \\
\hline Target genes & 266 & 152 & 258 & 676 \\
\hline
\end{tabular}

Table 5 Sequencing data of degradome library derived from 7DAP and 14 DAP grains

\begin{tabular}{|lll|}
\hline Types & Number & Percent (\%) \\
\hline Clean number & $10,620,205$ & 100.00 \\
\hline Unique number & $4,612,965$ & 43.44 \\
\hline
\end{tabular}

Table 6 miRNAs and targets identified by degradome sequencing

\begin{tabular}{|ll|}
\hline MiRNA name & Target genes \\
\hline tae-miR160 & Traes_1AL_147CF243C \\
\hline tae-miR160 & Traes_1BL_54CD82AC3 \\
\hline tae-miR160 & Traes_7AL_E3ADC8C38 \\
\hline tae-miR160 & Traes_7BL_18D335F08 \\
\hline tae-miR160 & Traes_7DL_55ADB3528 \\
\hline tae-miR156 & Traes_6BS_542961EA4 \\
\hline tae-miR1119 & Traes_6BS_4D03398A8 \\
\hline tae-miR1119 & Traes_6BS_222CE7DA7 \\
\hline tae-miR1119 & Traes_6BS_04A3400AF \\
\hline novel-miR0011 & Traes_3B_E7D2E8720 \\
\hline novel-miR0011 & Traes_3DS_C6D17D438 \\
\hline novel-miR0012 & Traes_3DS_2F5F2C276 \\
\hline novel-miR0012 & Traes_3B_8824DBB56 \\
\hline novel-miR0012 & Traes_3AS_7EEF1386F \\
\hline novel-miR0036 & Traes_7AS_2084DE83B \\
\hline novel-miR0075 & Traes_5AL_147EA9565 \\
\hline
\end{tabular}

\section{Figures}




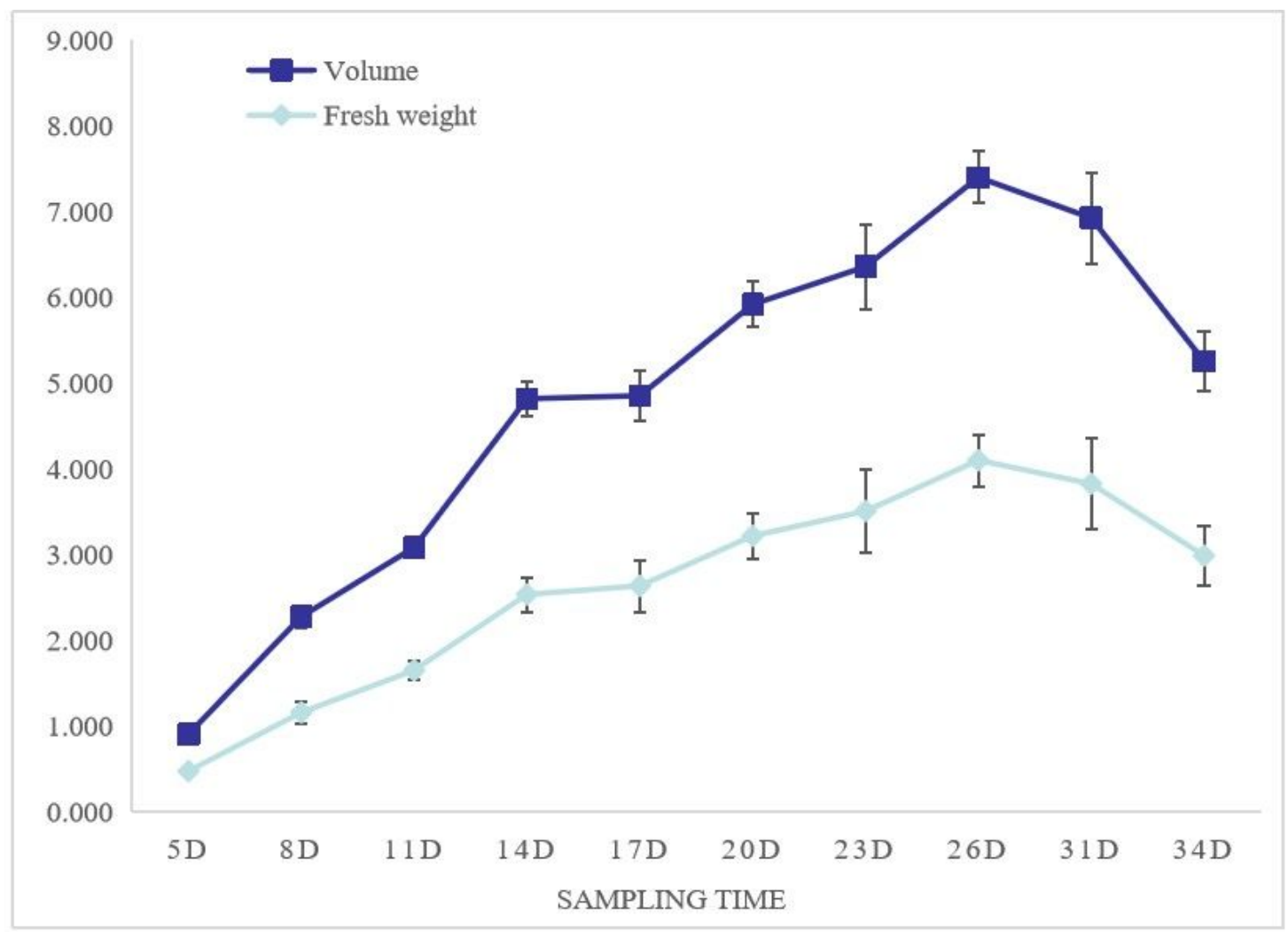

A
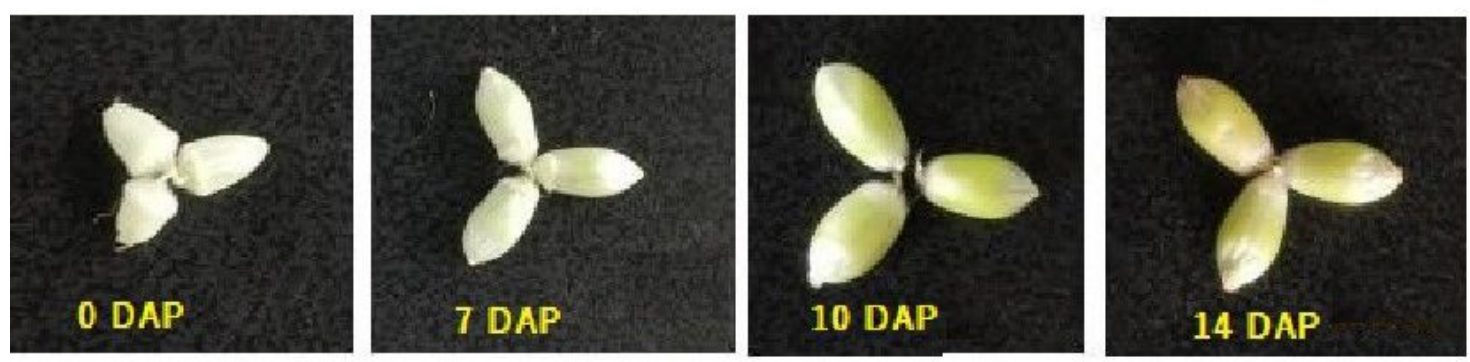

B

\section{Figure 1}

Phenotypic changes of developing grains at different days after pollination 


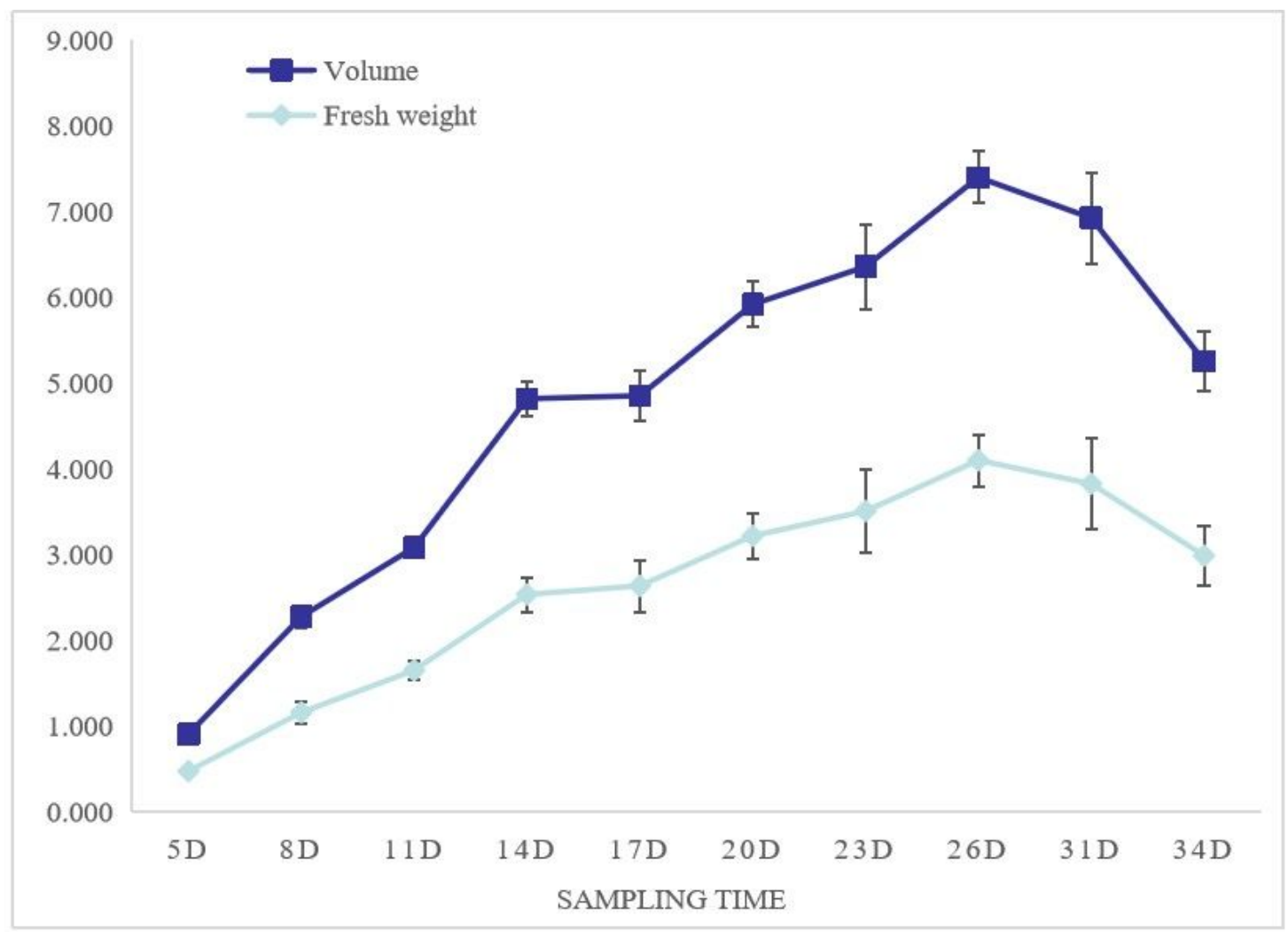

A
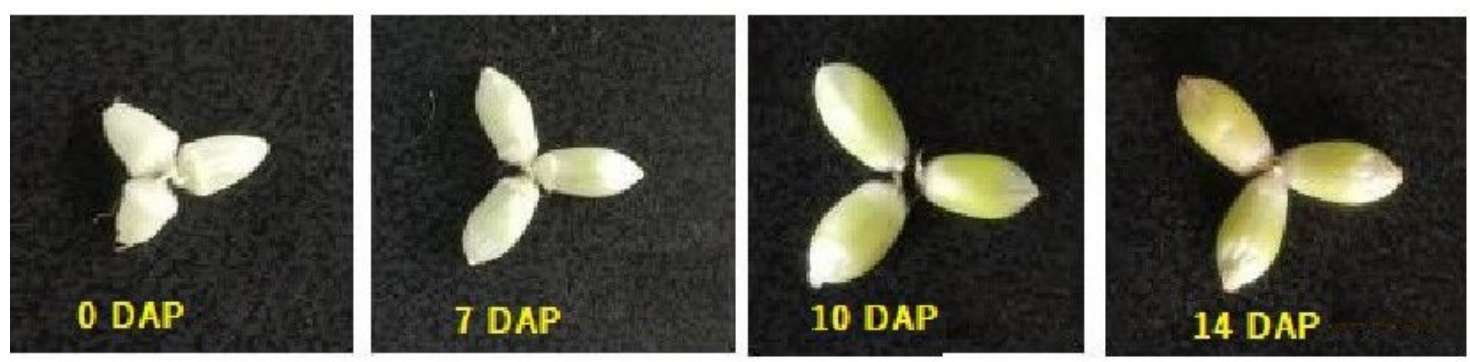

B

\section{Figure 1}

Phenotypic changes of developing grains at different days after pollination 


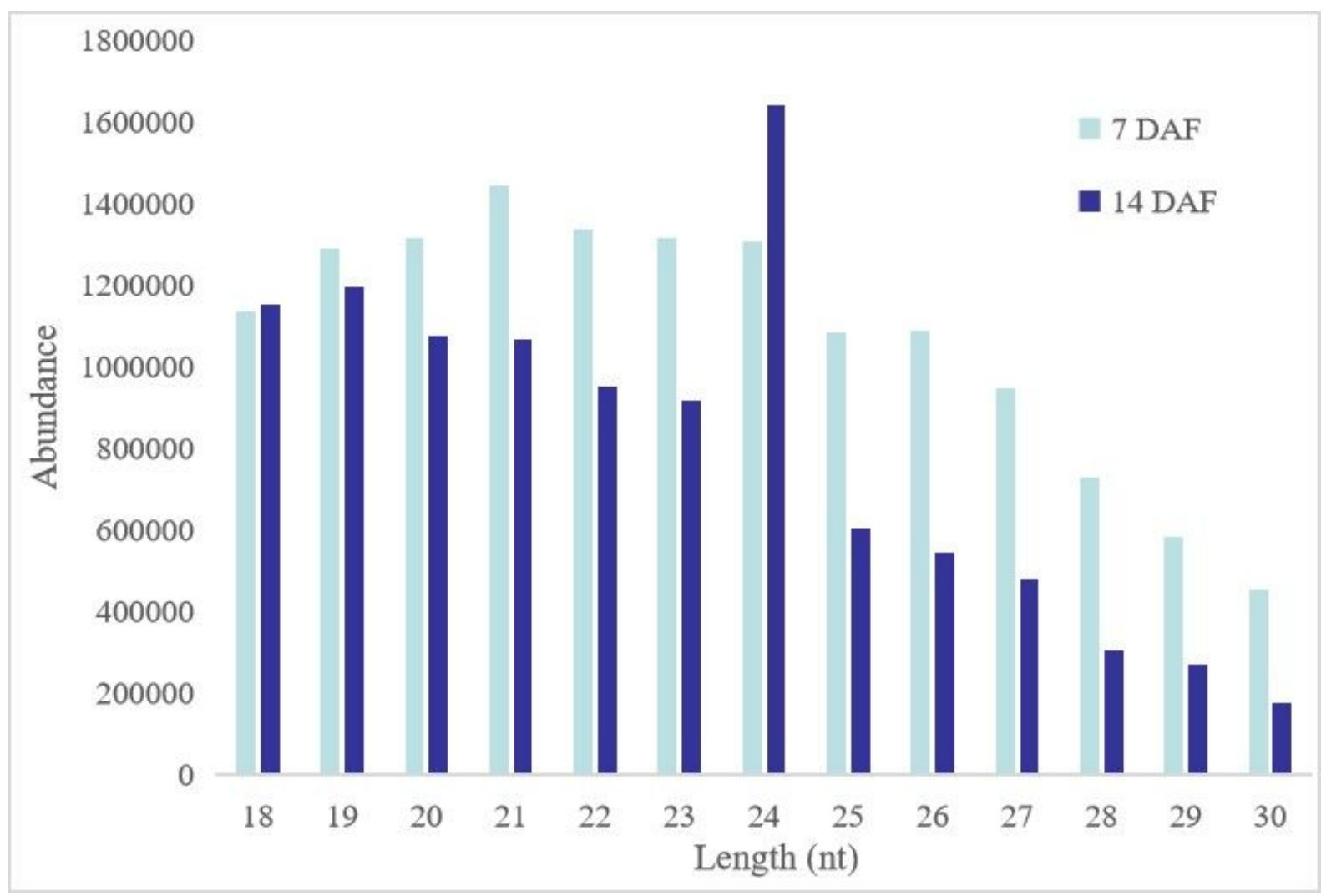

Figure 2

Length distributions of sRNAs in developing grains at 7DAP and 14 DAP

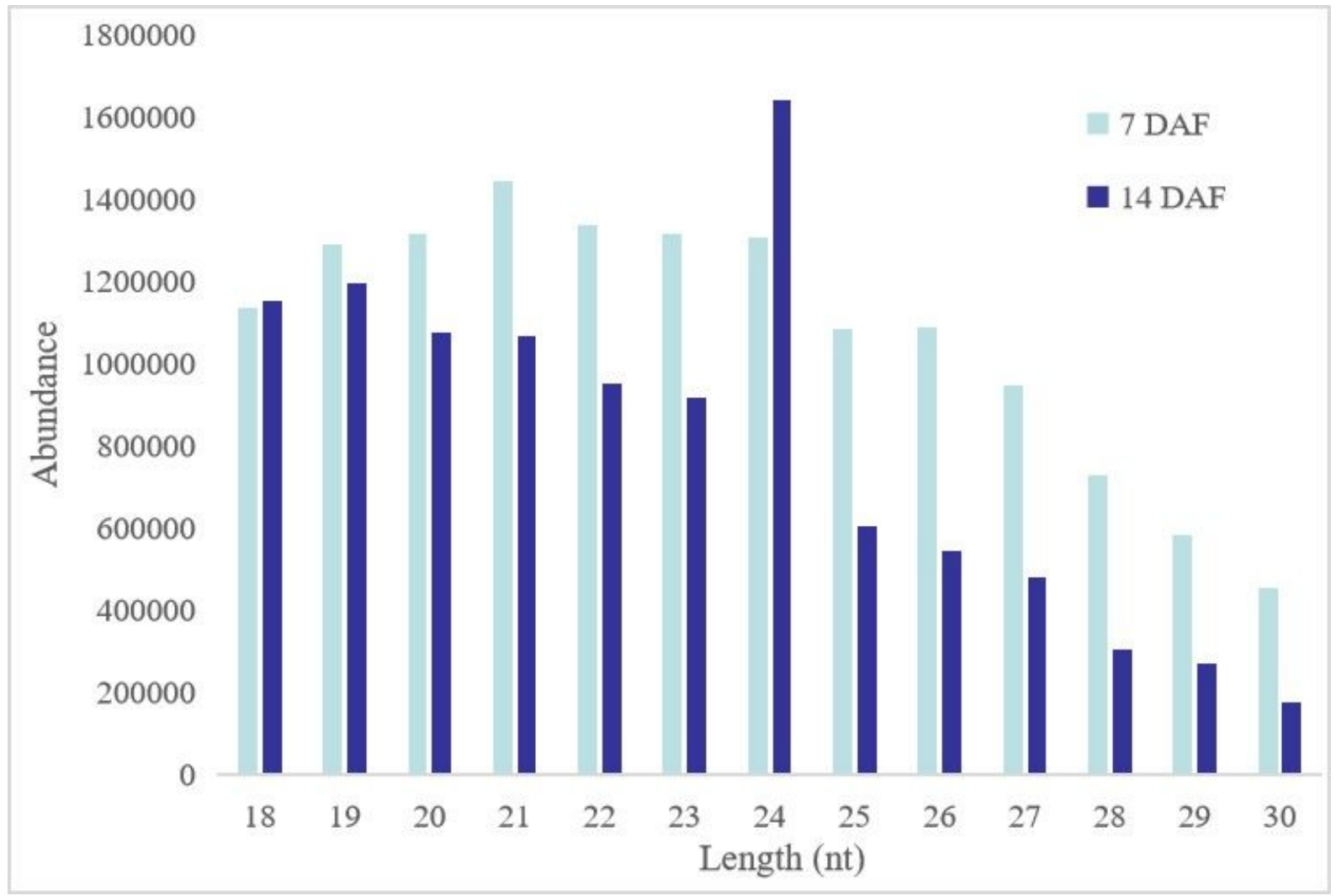

Figure 2

Length distributions of sRNAs in developing grains at 7DAP and 14 DAP

Page $18 / 29$ 


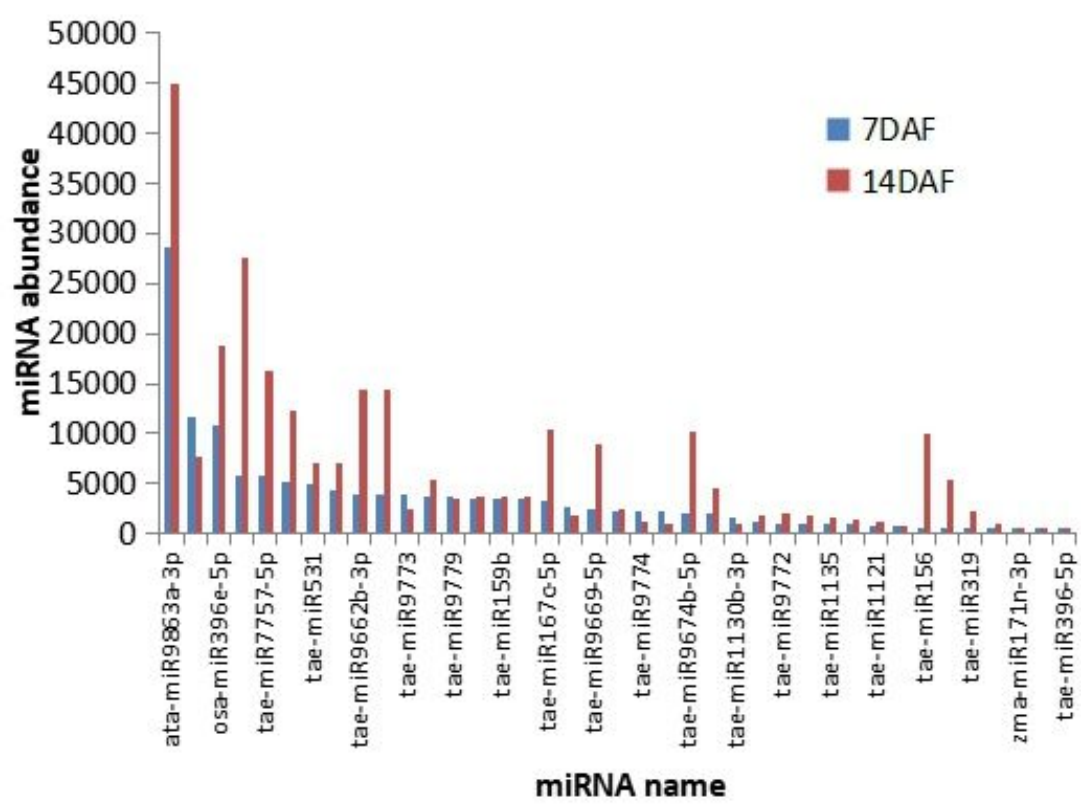

Figure 3

Most abundantly expressed known miRNAs in 7DAP and 14DAP grains

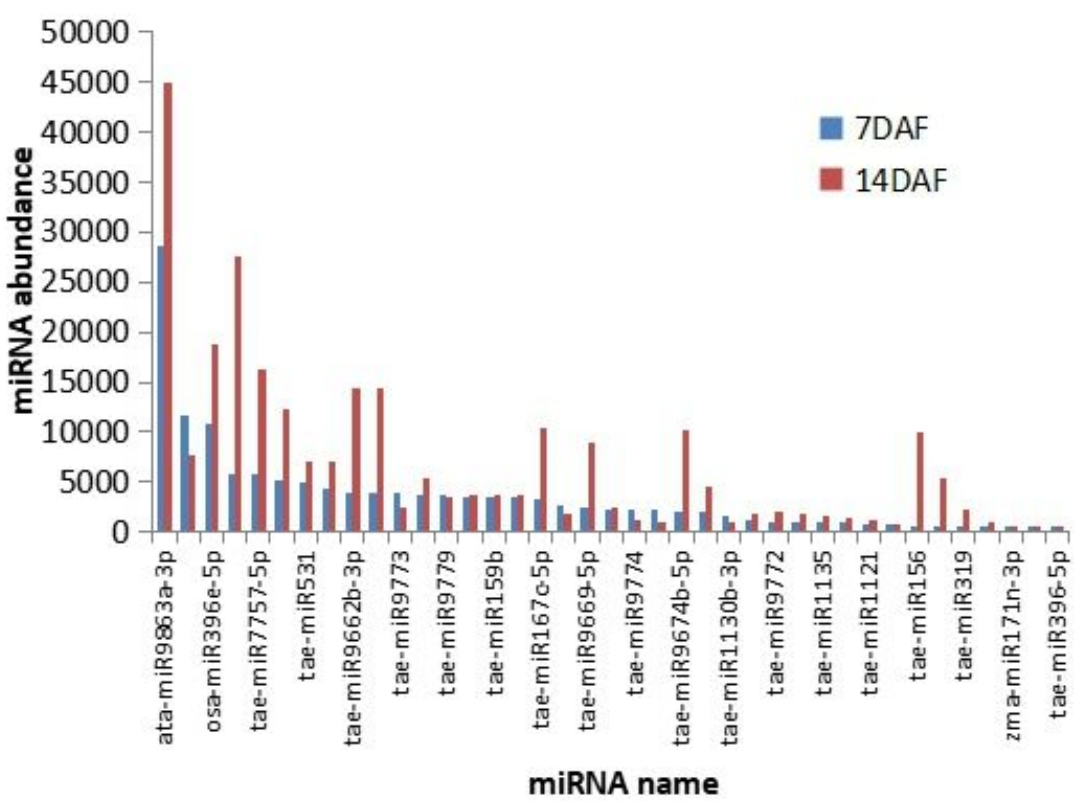

Figure 3

Most abundantly expressed known miRNAs in 7DAP and 14DAP grains 

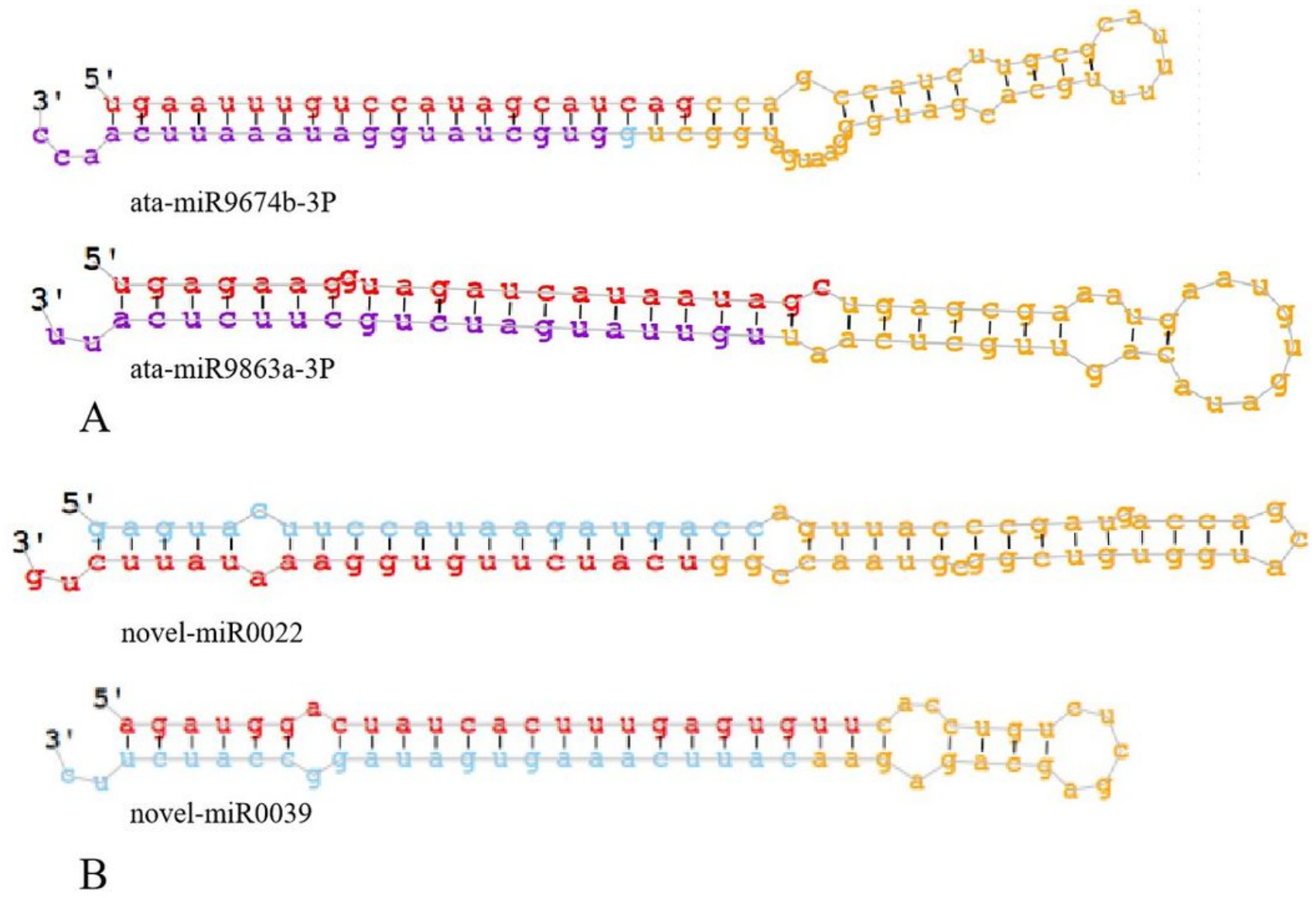

\section{Figure 4}

Secondary structures of identified representative miRNAs. Sense miRNAs (in red) and antisense miRNAs (in purple). A: Known miRNAs, first found in wheat; B: Novel miRNAs 

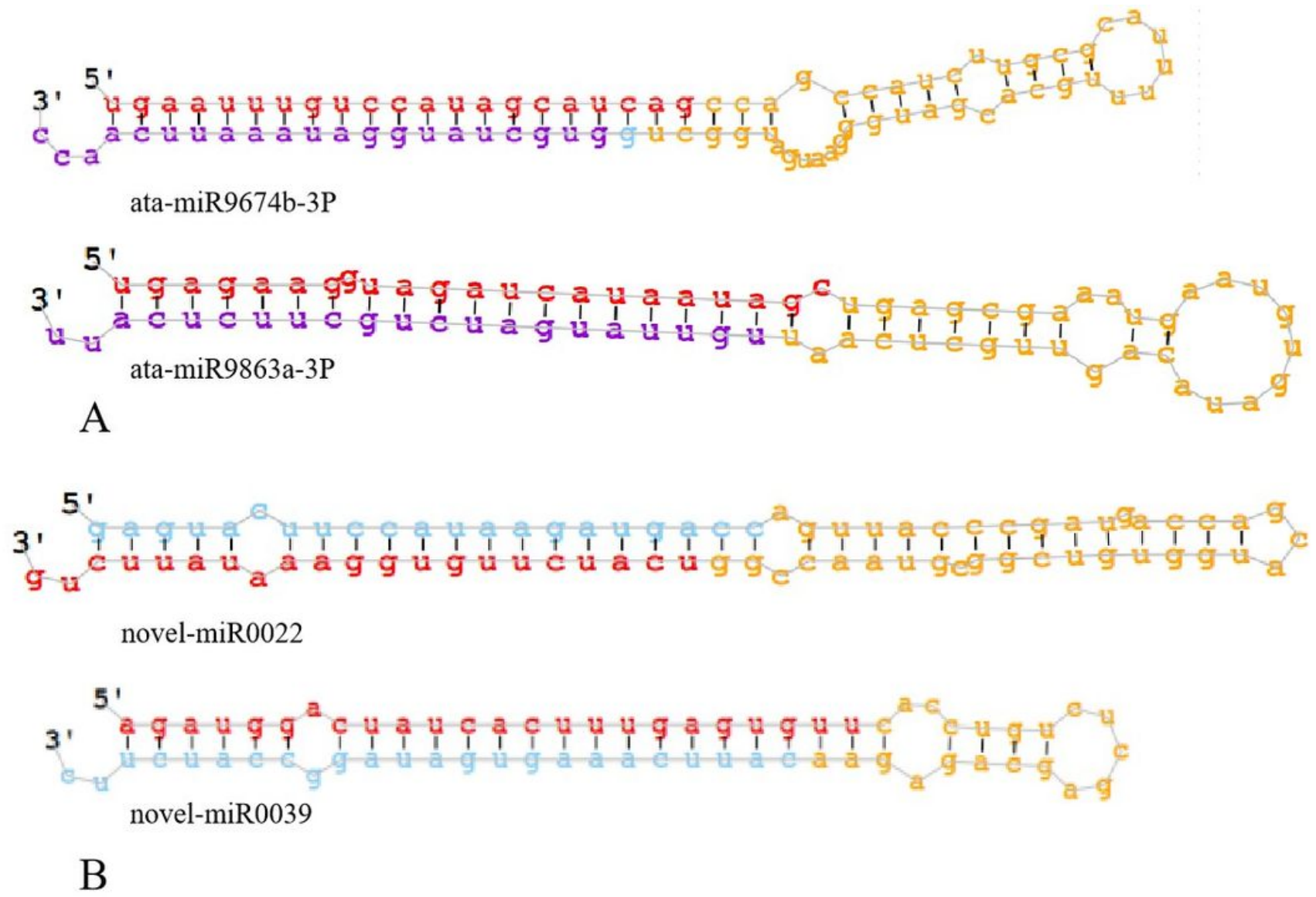

\section{Figure 4}

Secondary structures of identified representative miRNAs. Sense miRNAs (in red) and antisense miRNAs (in purple). A: Known miRNAs, first found in wheat; B: Novel miRNAs 

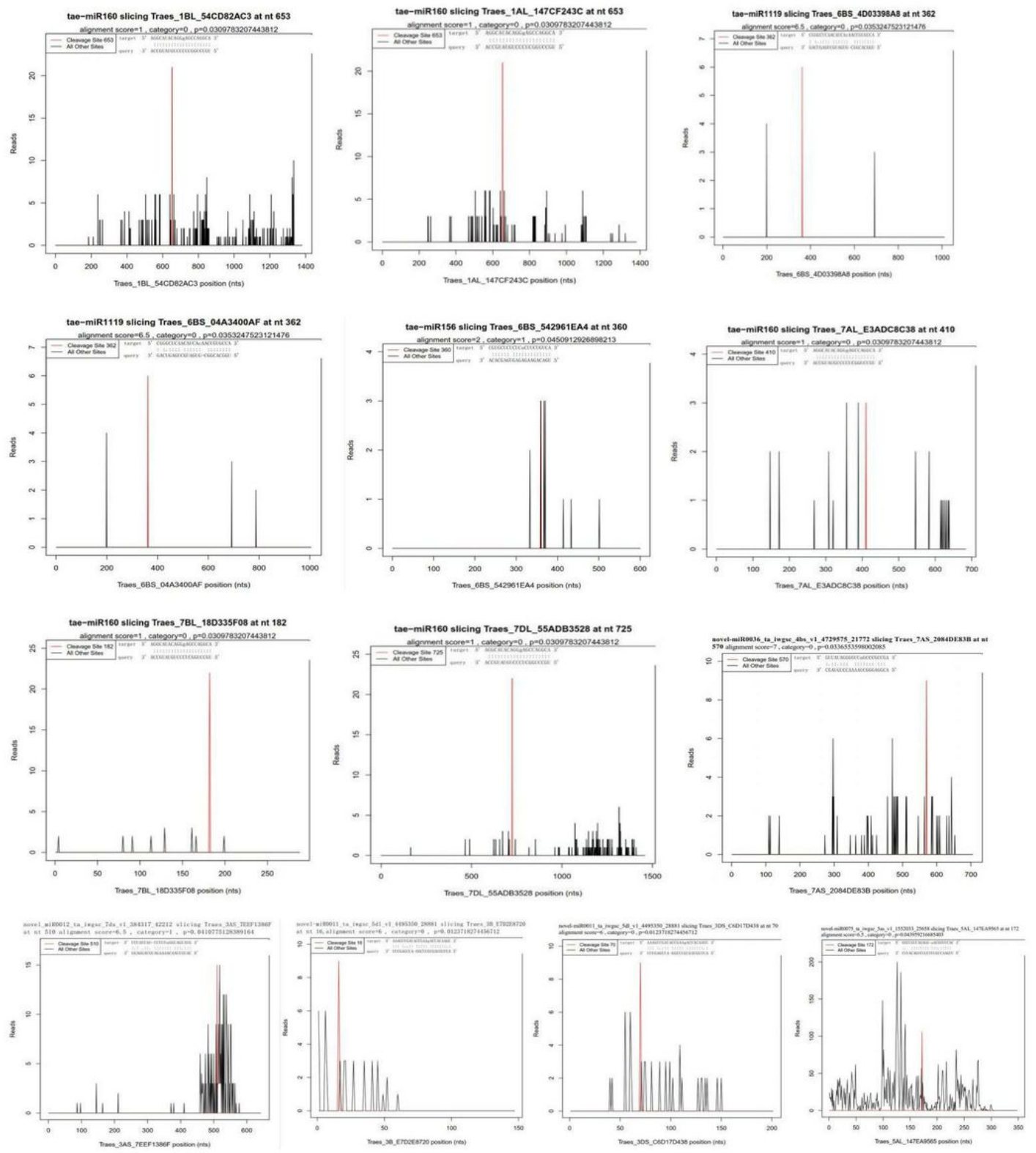

Figure 5

degraded sites of 13 annotated target genes predicted by degradome sequencing 

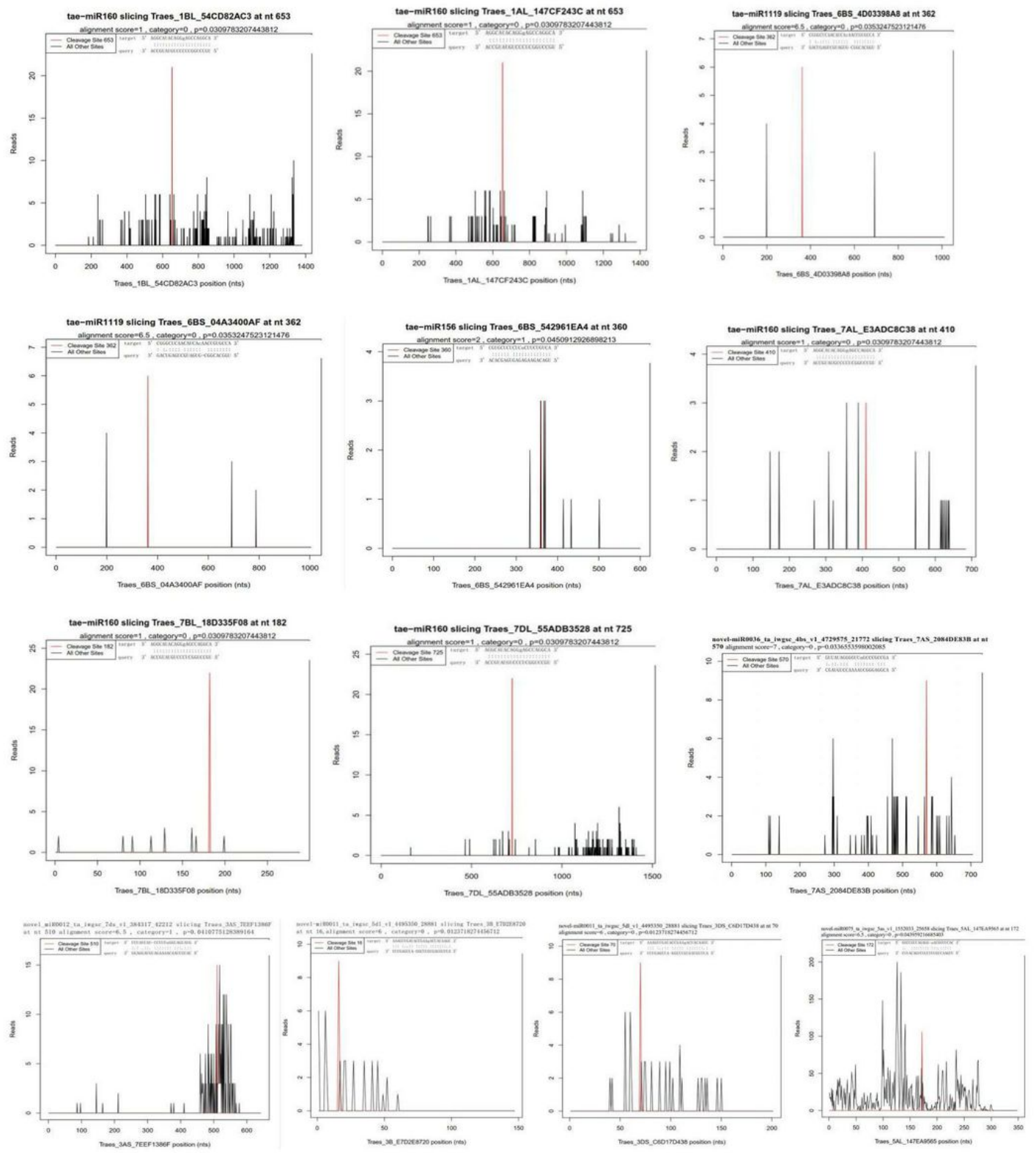

Figure 5

degraded sites of 13 annotated target genes predicted by degradome sequencing 

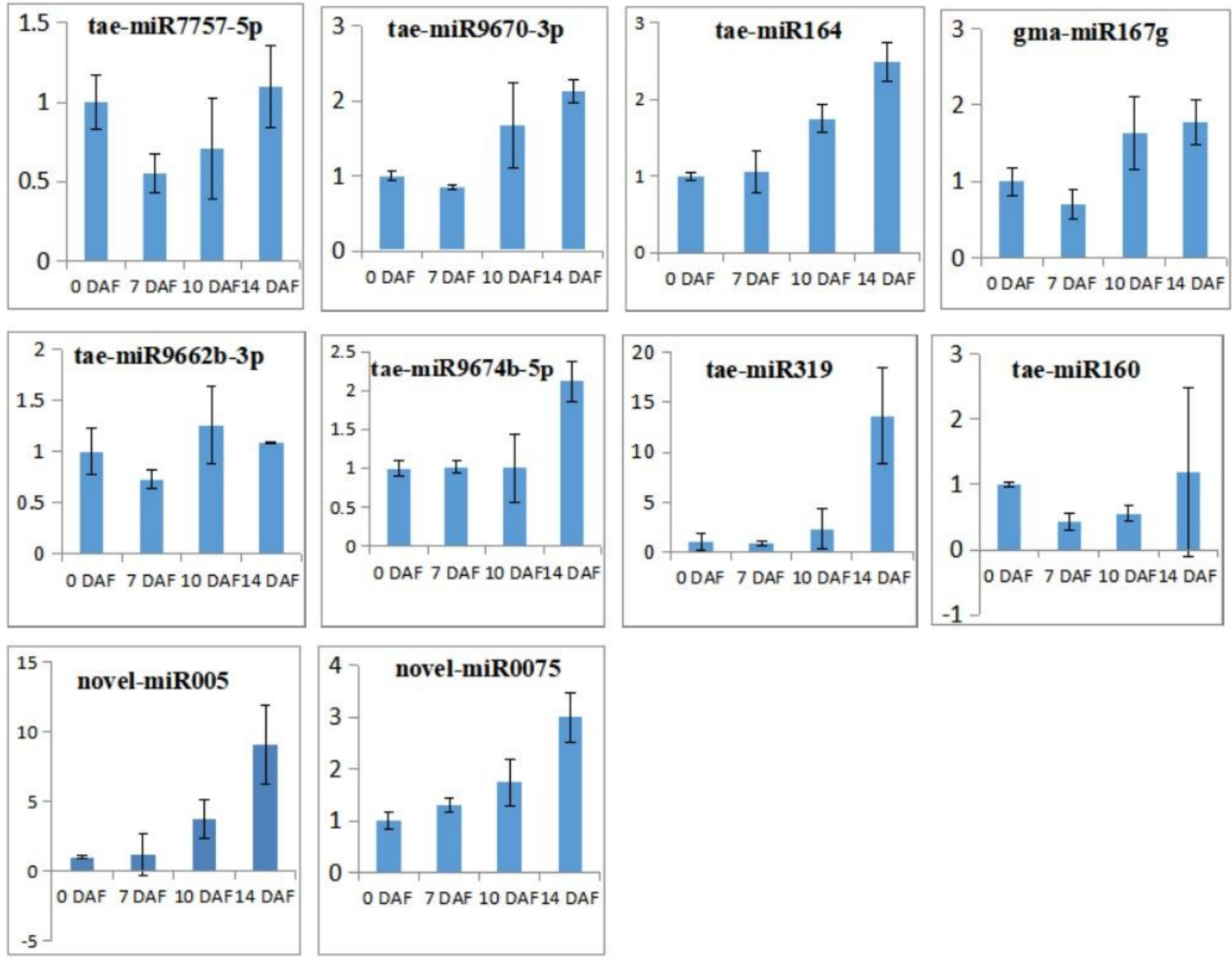

Figure 6

Validating of partial differentially expressed miRNAs by qRT-PCR 

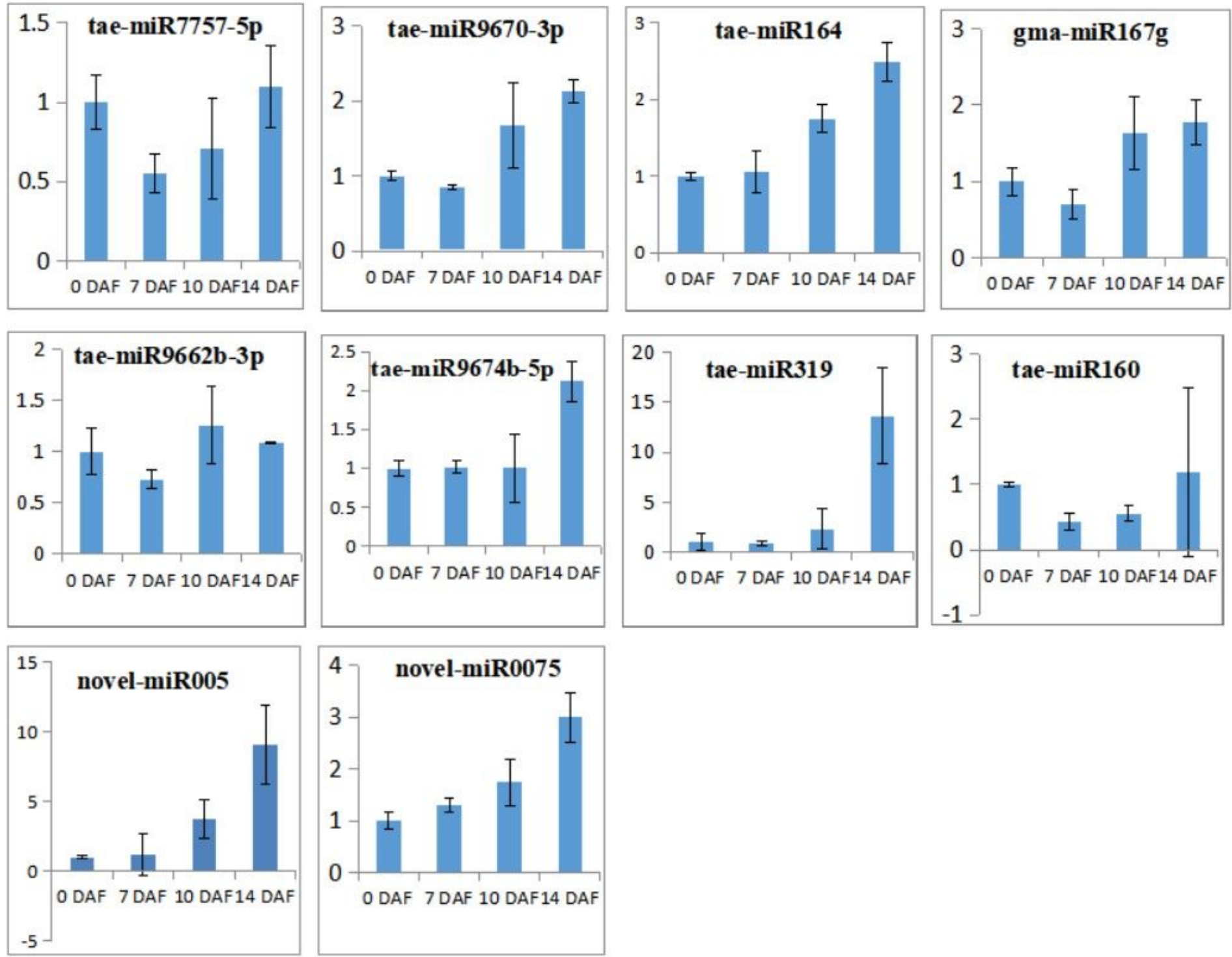

Figure 6

Validating of partial differentially expressed miRNAs by qRT-PCR 


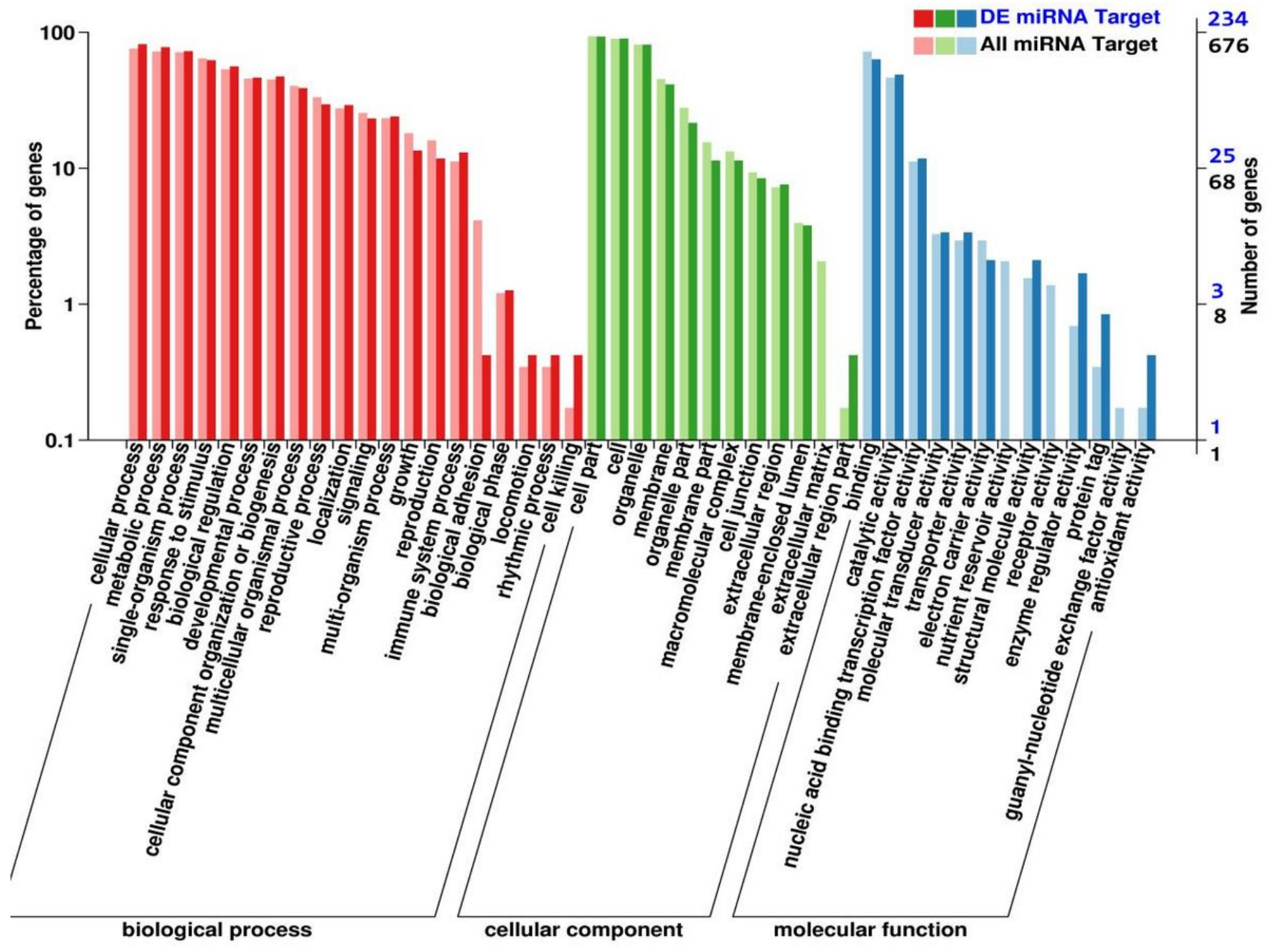

Figure 7

GO analysis of the differentially expressed miRNAs between 7 DAP and 14 DAP grains 


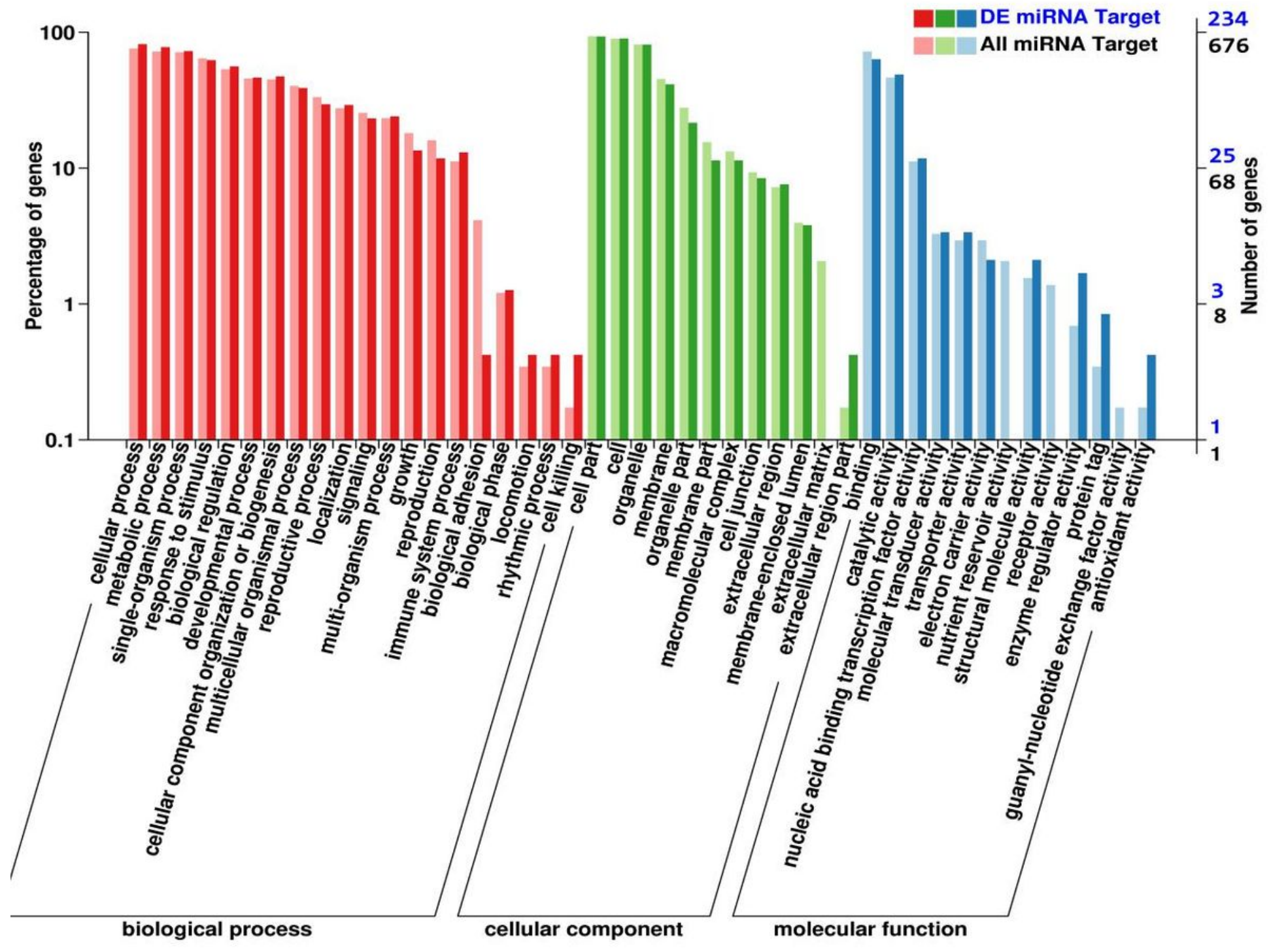

Figure 7

GO analysis of the differentially expressed miRNAs between 7 DAP and 14 DAP grains 

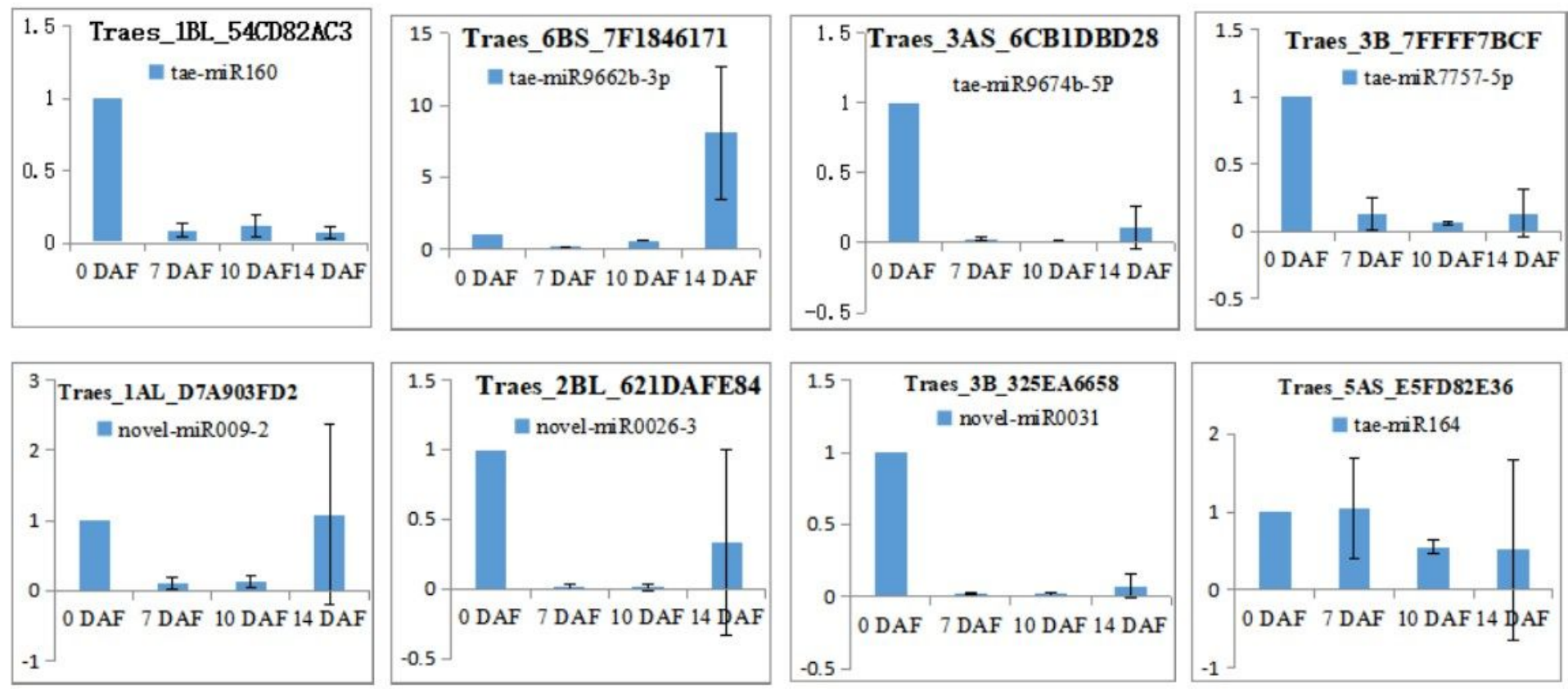

Figure 8

Confirmation of the expression patterns of partial miRNA targets by qRT-PCR
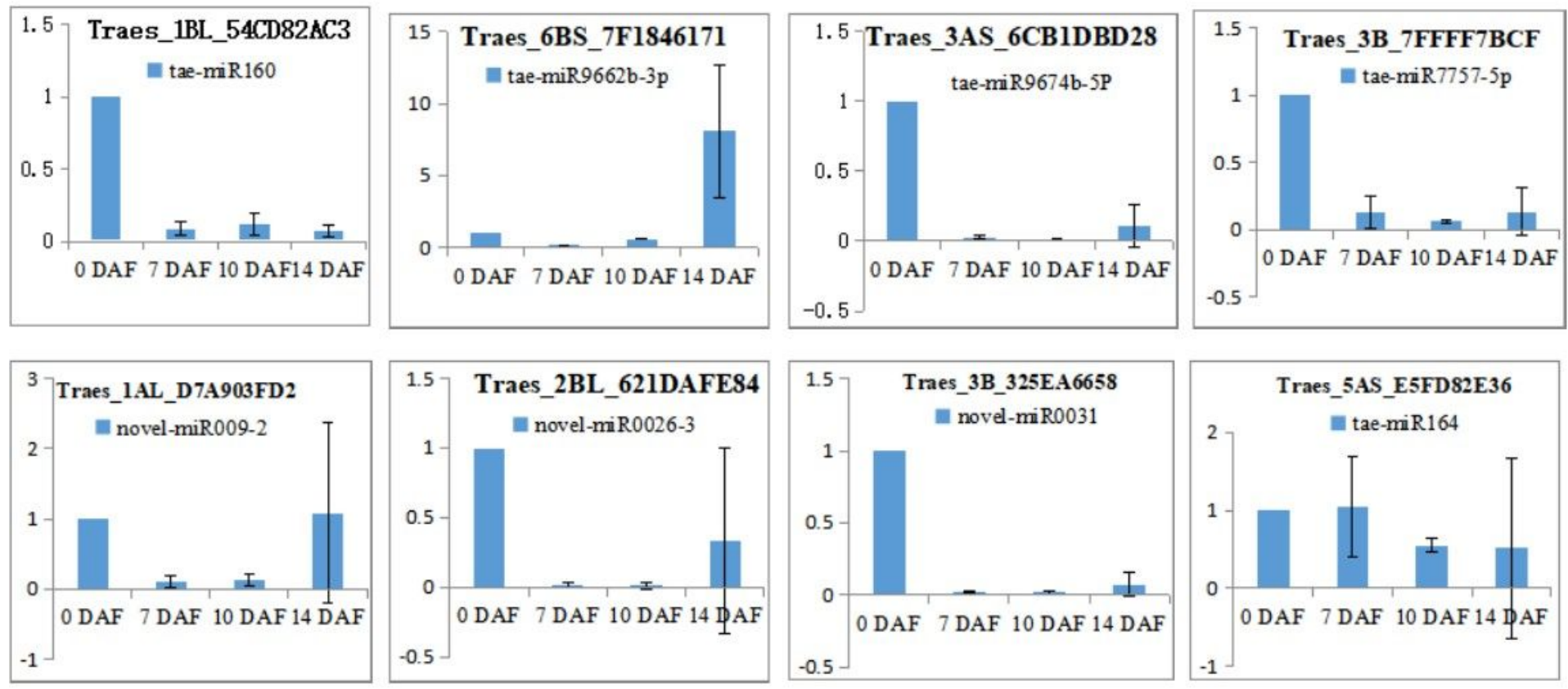

Figure 8

Confirmation of the expression patterns of partial miRNA targets by qRT-PCR

\section{Supplementary Files}

This is a list of supplementary files associated with this preprint. Click to download.

- Additionalfile1.xlsx

- Additionalfile1.xlsx

- Additionalfile10.xIsx 
- Additionalfile10.xIsx

- Additionalfile2.xls

- Additionalfile2.xls

- Additionalfile3.pdf

- Additionalfile3.pdf

- Additionalfile4.xls

- Additionalfile4.xls

- Additionalfile5.pdf

- Additionalfile5.pdf

- Additionalfile6.xIsx

- Additionalfile6.xlsx

- Additionalfile7.xls

- Additionalfile7.xls

- Additionalfile8.xlsx

- Additionalfile8.xlsx

- Additionalfile9.xlsx

- Additionalfile9.xlsx 